UNIVERSIDADE DE SÃO PAULO

FACULDADE DE MEDICINA DE RIBEIRÃO PRETO

Marcela Kazue Hassumi

\title{
DETECÇÃO DO HPV E AVALIAÇÃO IMUNOISTOQUÍMICA DE PROTEÍNAS REGULADORAS DO CICLO CELULAR EM CARCINOMAS INVASIVOS DE LARINGE COM E SEM METÁSTASES
}

Dissertação de Mestrado apresentada ao Departamento de Patologia da Faculdade de Medicina de Ribeirão Preto da Universidade de São Paulo para obtenção do Título de Mestre em Ciências Médicas. Opção: Patologia Experimental.

Ribeirão Preto 2008 
Aos meus pais, Mitsuo Hassumi e Edina Shimizu Hassumi, meu porto seguro, por me ensinarem buscar a felicidade, pelo exemplo de honestidade, de caráter e por todo amor, carinho, dedicação e incentivo constante. Obrigada por estarem sempre presentes em cada momento da minha vida. Sem vocês eu nada seria.

Ao meu irmão Márcio Yukio Hassumi, minha cunhada Lorena Karla Rodrigues Silva Hassumi e minha afilhada Vitória Yukari R. S. Hassumi por me ensinarem que a distância não afasta os corações. Obrigada pelo apoio e estímulo sempre.

À minha querida amiga Neide Terezinha Gonçalves por me ensinar a importância da persistência, por cada história que vivemos por cada riso e por cada lágrima. Obrigada por todo cuidado, preocupação, afeto e carinho de mãe que sempre teve comigo. 
AGRADECIMENTOS 
À Deus, por cada momento vivido e por sempre iluminar meu caminho.

Ao Prof. Dr. Edson Garcia Soares por se tornar um grande amigo nesta caminhada, pela orientação, confiança e apoio ao meu desenvolvimento científico.

À amiga Ana Maria da Rocha pela amizade, apoio técnico, dedicação e zelo.

Às amigas da Secretaria do Departamento de Patologia Rosângela M. Castania de Paiva, Camila de Luca Zambonini e Edna Pio da Silva (sempre presente), pela amizade especial, por todo carinho e atenção ao longo destes dias.

Ao amigo Antônio de Pádua Martins pela convivência, pelo bom humor e as risadas.

Aos amigos Daniel Barcellini, Deise Lúcia Chesca Simões e Deisy Mara Silva pela amizade e apoio.

Aos amigos do Arquivo do Departamento de Patologia Décio A. Barrionovo Filho e César Alberto Brigato Jr. pela atenção e colaboração.

Às queridas amigas Luane Taísa da Costa Barros, Jussara de Sousa Ribeiro Bettini, Fabiana Alves de Miranda, Márcia Cristina Monteiro Guimarães, Renata Toscano Simões e Régia Caroline P. Lira pelo valor da amizade e companheirismo nesta caminhada.

Aos amigos Aline Turatti, Karina M. A. da Mata, Cleverson Rodrigues Fernandes e Patrícia Modiano pelo apoio e amizade.

Ao amigo Celso Mendes Teixeira Júnior pela atenção e apoio na estatística.

À Profa. Dra. Christiane Pienna Soares, pelo apoio e colaboração.

Ao Comitê de Ética em Pesquisa do Hospital das Clínicas da Faculdade de Medicina de Ribeirão Preto pelo apoio e aprovação deste trabalho.

A CAPES pelo auxílio científico e financeiro.

A todos que de alguma maneira colaboraram para a realização deste trabalho. 
"Compreendi que a vida não é uma sonata que, para realizar sua beleza, tem de ser tocada até o fim. Dei-me conta, ao contrário, de que a vida é um álbum de minissonatas. Cada momento de beleza vivido e amado, por efêmero que seja, é uma experiência completa que está destinada à eternidade. Um único momento de beleza e de amor justifica a vida inteira".

Rubem Alves 
HASSUMI, M.K. Detecção do HPV e avaliação imunoistoquímica de proteínas reguladoras do ciclo celular em carcinomas invasivos de laringe com e sem metástases. 2008. 75p. Dissertação (Mestrado em Patologia Experimental) - Faculdade de Medicina de Ribeirão Preto, Universidade de São Paulo, Ribeirão Preto.

O mecanismo de oncogênese na laringe pode ser controlado por vários fatores, entre eles fatores envolvidos na regulação do ciclo celular e outros de risco, tais como exposição prolongada ao fumo e álcool. O desenvolvimento do câncer de laringe também pode estar associado à infecção pelo HPV. Este estudo, análise imunoistoquímica quantitativa de p53, p27 e Mdm2, foi realizado em 54 pacientes com carcinoma invasivo de laringe subdivididos em: carcinoma sem metástase (laryngeal squamous cell carcinoma without metastasis - LSCC ${ }^{\mathrm{WT}}$ ), com metástase (laryngeal squamous cell carcinoma with metastasis - LSCC ${ }^{\mathrm{W}}$ ) e linfonodos cervicais (limph nodes biopsies - LB). A detecção e tipificação do HPV foram realizadas pela reação em cadeia da polimerase (PCR) e os tipos de HPV avaliados foram HPV 6, 11, 16, 18, 31 e 33. Na análise quantitativa, alta expressão de p53, p27 e Mdm2 foi observada nos grupos $\mathrm{LSCC}^{\mathrm{W}}$ e LSCC $^{\mathrm{WT}}$ assim como nas biópsias dos linfonodos cervicais, indicando que a avaliação dessas proteínas poderia não discriminar carcinomas de laringe metastáticos e nãometastáticos. Detecção do HPV foi verificada em apenas $7.4 \%$ dos casos. Dentre os pacientes HPV positivos, verificou-se expressão negativa de p53. Por outro lado, alta expressão de p27 e Mdm2 foi observada. Em conclusão, a avaliação quantitativa de p53, p27 e Mdm2 não permite traçar um perfil complementar em lesões metastáticas de laringe.

Palavras-chave: p53, p27, Mdm2, metástase, carcinoma de laringe. 
HASSUMI, M.K. HPV detection and immunohistochemical expression of cell cycle regulating proteins in metastatic and non-metastatic laryngeal carcinoma. 2008. 75p. Dissertation (Mastery in Experimental Pathology) - Faculty of Medicine of Ribeirão Preto, University of São Paulo, Ribeirão Preto.

The mechanism of larynx oncogenesis could be controlled by various factors, most of them involved in cell cycle regulation and other risk factors such as smoking and alcohol abuse. The development of laryngeal carcinoma is associated with human papillomavirus (HPV) infection. In this study, quantitative immunohistochemistry was perfomed for p53, p27 and Mdm2 in 54 patients with invasive laryngeal squamous cell carcinoma without metastasis $\left(\mathrm{LSCC}^{\mathrm{WT}}\right)$, with metastasis $\left(\mathrm{LSCC}^{\mathrm{W}}\right)$ and cervical lymph nodes (LB). HPV detection and typing was performed by PCR and the HPV types evaluated were HPV 6, 11, 16, 18, 31 and 33. In the quantitative analysis higher p53, p27 and Mdm2 expression was observed in both $\mathrm{LSCC}^{\mathrm{W}}$ and $\mathrm{LSCC}^{\mathrm{WT}}$, as well in cervical lymph node biopsies with metastasis, may indicating that evaluation of these proteins may not discriminate between metastatic and non-metastatic laryngeal carcinoma. HPV was found in $7.4 \%$ of the cases. Among HPV-positive patients, p53 expression was negative. On the other hand, high p27 and Mdm2 expression was observed. In conclusion, these data suggest that quantitative evaluation of p53, p27 and Mdm2 does not permit to determine a complementary profile in metastatic laryngeal lesions.

Keywords: p53, p27, Mdm2, metastasis, laryngeal carcinoma 
1. Introdução 14

O Ciclo Celular e o Câncer $\quad 15$

1.2 O Câncer de Laringe $\quad 16$

a) O Papilomavírus Humano (HPV) 18

1.2 b) Relação entre HPV e as lesões proliferativas de laringe 19

1.3 Reguladores do Ciclo Celular 21

1.3 a) p53 e o Câncer 22

1.3 b) p27 e o Câncer 23

1.3 c) Mdm2 e o Câncer 24

1.4 HPV e os Reguladores do Ciclo Celular 25

2. OBJETIVOS 27

3. CASUÍSTICA E MÉTODOS 29

Aspectos éticos 30

Casuística 30

3.3 Reação de Imunoistoquímica (p53, p27 e Mdm2) 31

3.3a) Controles 32

3.3b) Aquisição de imagens e Análise Quantitativa de p53, p27 e Mdm2 32

3.4 Detecção e Tipagem do HPV 33

3.4.a) Extração do DNA genômico de tecido parafinizado 33

3.4.b) Amplificação do HPV e do gene de betaglobina 34

3.4 c) Amplificação com primers tipo específicos 35

3.5 Análise Estatística 35

4. RESULTADOS 37

Câncer de laringe e parâmetros clínicos 38

Detecção e tipagem do HPV 39

Tipos de HPV e expressão imunoistoquímica do p53, p27 e Mdm2 40

Câncer de laringe e expressão imunoistoquímica do p53, p27 e Mdm2 44

5. DISCUSSÃO 45

6. CONCLUSÕES

7. REFERÊNCIAS BIBLIOGRÁFICAS

$\begin{array}{ll}\text { ANEXOS } & 75\end{array}$ 


\subsection{O CICLO CELULAR E O CÂNCER}

O ciclo celular é dividido em 4 fases: G1 que é a preparação para síntese de DNA, S que é a fase de síntese, G2 onde há o preparo para a divisão celular e por fim a fase M de mitose (SHEER, 1996). No processo de divisão celular, a ação coordenada dos complexos CDKs (cyclin-dependent kinases)/ciclinas, colabora na sucessão de eventos moleculares em cada fase do ciclo celular. Em cada fase, um complexo CDK/ciclina específico é responsável por coordenar às atividades celulares daquele momento. Por sua vez, as proteínas inibidoras de CDKs (CKI - cyclin - kinase inhibitors) controlam a ação desse complexo, colaborando para a interrupção do ciclo celular e reparo (ALBERTS et. al, 2002).

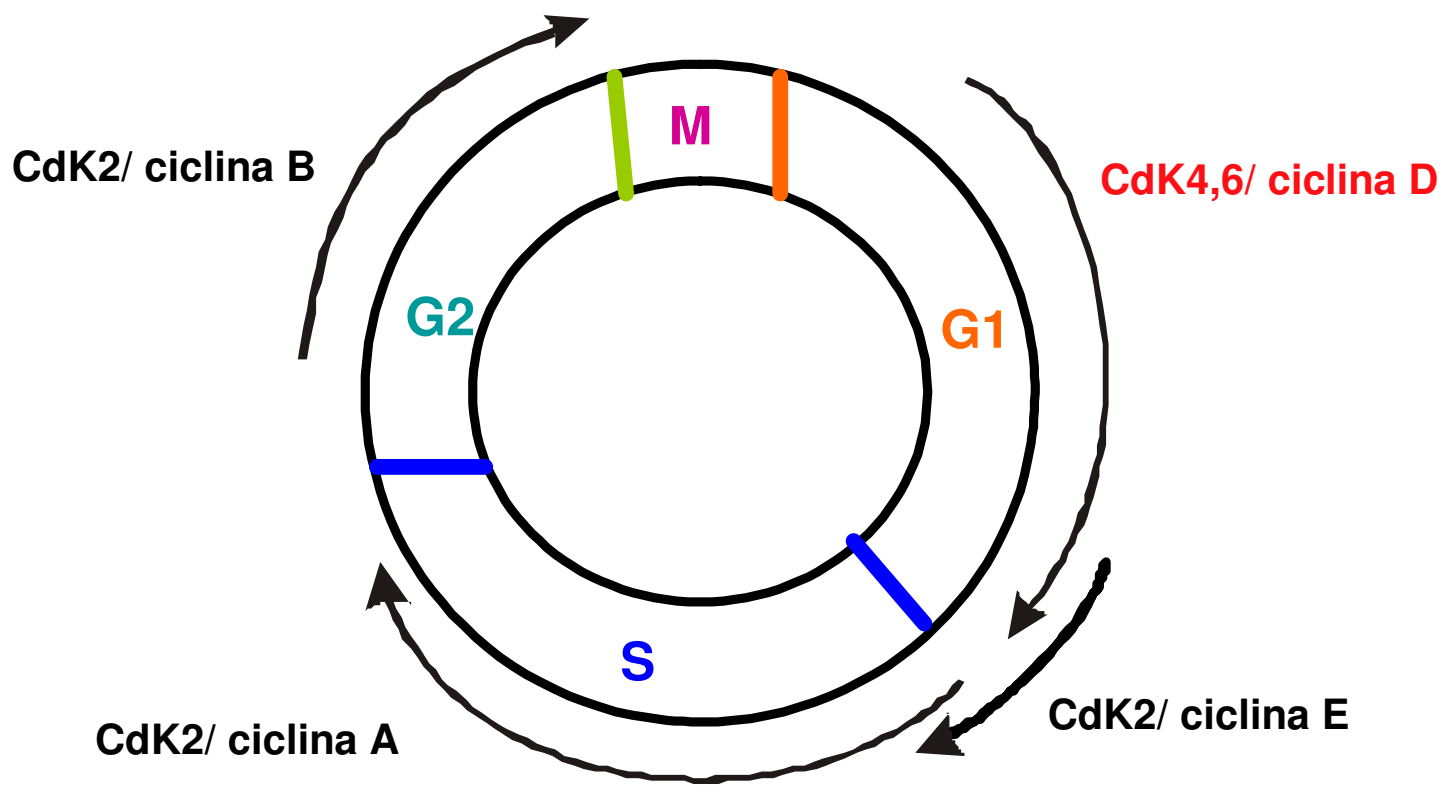

Representação esquemática do complexo ciclina/CDK nas diferentes fases do ciclo celular (COOPER \& HAUSMAN, 2003).

Desta forma, as proteínas CKI têm função importante de supressão tumoral, impedindo a transformação maligna nas células normais.

Nas células normais, os danos produzidos no material genético podem ser sinalizados e corrigidos, ativando mecanismos de controle da progressão do ciclo celular, denominados 
checkpoints, quando as condições internas são desfavoráveis à divisão celular. Além de controlar o bloqueio ou retardo do ciclo celular, os checkpoints fazem parte de uma ampla rede de resposta ao dano celular, que pode incluir desde a ativação de mecanismos de reparo, ativação transcricional até a apoptose (COOPER e HAUSMAN, 2003). Este último evento ocorre nos casos onde a extensão do dano impossibilita a sua correção (ZHOU e ELLEDGE, 2000). A desregulação desses eventos celulares quer pela desativação dos checkpoints ou pela inibição dos mecanismos de apoptose, pode favorecer a perpetuação de alterações, contribuindo para a transformação maligna ou câncer (COOPER e HAUSMAN, 2003).

Mundialmente considerado como um problema de saúde pública, o câncer representa a terceira causa de morte no Brasil e segundo o Instituto Nacional do Câncer (INCA) estima-se que aproximadamente 470.000 novos casos da doença sejam diagnosticados no ano de 2008 . O câncer de pele do tipo não melanoma (115 mil novos casos) será o mais incidente na população brasileira, seguido pelos tumores de próstata (49 mil), de mama feminina (49 mil), de pulmão (27 mil), de cólon e reto (27 mil), de estômago (22 mil) e de colo de útero (19 mil). Acompanhando o mesmo perfil observado no resto do mundo, no Brasil os cânceres de próstata e pulmão serão os mais incidentes no sexo masculino, e os cânceres de mama e colo de útero, no sexo feminino (INCA, 2008).

\subsection{CÂNCER DE LARINGE}

A laringe é um órgão formado por um arcabouço cartilaginoso, pela musculatura intrínseca e por revestimento epitelial interno. Do ponto de vista filogenético, a função primordial da laringe é a proteção das vias aéreas inferiores, para evitar a entrada de líquidos e alimentos. Também participa no mecanismo da fonação, onde a voz é produzida pela vibração das cordas vocais. (HIRANO e SATO, 1993). 
Dentre os diferentes tipos de neoplasias malignas, o câncer de laringe é o mais comum da região da cabeça e pescoço, representando cerca de $25 \%$ dos tumores malignos que acometem esta área e $2 \%$ de todas as doenças malignas. No mundo, estima-se um total de 159.000 novos casos de câncer de laringe a cada ano, sendo mais comum no sexo masculino numa prevalência de 7:1. (PARKIN et al, 2005). Segundo Ferlay e colaboradores (2001) a Europa é uma das áreas de maior risco para câncer de laringe sendo a maioria dos carcinomas diagnosticados na faixa etária de 65 anos ou mais e com um pico de incidência na sexta e sétima década de vida.

Na população brasileira ocorrem anualmente aproximadamente 8000 novos casos e 3000 mortes, sendo 3,8\% homens e $0.6 \%$ mulheres. A cidade de São Paulo exibe uma das mais altas taxas de incidência de câncer de laringe no mundo (WÜNSCH FILHO, 2004). No Brasil, segundo INCA, as regiões sudeste, sul e centro-oeste do Brasil são as mais afetadas, apresentando entre 1995 e 1999, uma taxa de mortalidade por 100.000 homens de 2,26 a 5,57 e de 0,39 a 0,63 por 100.000 mulheres.

O câncer de laringe pode ser considerado uma doença multifatorial influenciada tanto por fatores ambientais como por estilo de vida. Consumo de álcool e hábito tabagista são os principais fatores de risco (DOSEMECI et al., 1997; ALTIERI et al., 2005). Adicionalmente, o consumo associado de álcool e cigarro pode multiplicar os riscos para a doença (TUYNS et al., 1988; TALAMINI et al., 2002). Outros fatores de risco associados ao câncer de laringe como refluxo gastroesofágico, exposição a elementos químicos devido a danos ocupacionais e infecção pelo Papilomavírus Humano (HPV) podem ser considerados como co-fatores pra este tipo de câncer (KREIMER et al., 2005; QADEER et al., 2006; SARTOR et al., 2007). 


\section{2 a) O PAPILOMAVÍRUS HUMANO (HPV)}

O HPV é um vírus pertencente à família Papovaviridae, envolvido por um capsídeo composto de duas proteínas estruturais, que se organizam em 72 subunidades (capsômeros) num arranjo icosaédrico. Este pequeno vírus, com 55 nanômetros (nm) de diâmetro possui um genoma circular, em dupla fita de DNA, que contém cerca de 8000 pares de base (pb) e peso molecular de $5,2 \times 10^{6}$ daltons (ZUR HAUSEN, 2002). O genoma do HPV contém três regiões: a primeira composta pelos genes denominados $\mathrm{E}$ (early), que são expressos precocemente no ciclo do vírus; a segunda é representada pelos genes L (late), que são expressos nos estágios mais tardios. Essas duas regiões são responsáveis pela codificação de proteínas virais e representam, respectivamente, $45 \%$ e $40 \%$ do genoma viral. A terceira região é denominada de região de controle de replicação (LCR - Long Controll Region) que se localiza no final de L1 e início de E6. (ZUR HAUSEN, 2002).

A região E (early) é constituída por oito genes (E1 a E8), sendo que E3 e E8 ainda não têm função conhecida. Essa região codifica as proteínas envolvidas na replicação viral e, nos HPVs de alto risco, são responsáveis pelo processo de imortalização celular. A região L (late) codifica as proteínas estruturais necessárias para a formação do capsídio viral. A região LCR é uma região regulatória que contém os elementos regulatórios necessários para transcrição do vírus incluindo o promotor E e a origem de replicação viral (ori) (ZUR HAUSEN, 2002; HEISE, 2003).

As regiões L1 e L2 possuem seqüência gênica altamente conservada entre todos os tipos de HPV e são responsáveis pela codificação de proteínas constituintes do capsídio viral, as quais respondem por sua antigenicidade. Duas proteínas estruturais compõem o capsídeo do HPV: a proteína principal L1, de 54 Kilo Daltons (KDa) e a proteína secundária L2, de 52 KDa (MUNGER e HOWLEY,2002; ZUR HAUSEN, 2002). 
A região não codificadora, denominada long control region (LCR) ou upstream regulatory region (URR), possui aproximadamente 500 a 1000 pb e está localizada entre os genes L1 e o início da região E6. Essa região representa 15\% do genoma viral e contém genes responsáveis pelo controle de replicação do HPV (SOUZA, DOSTATNI, YANIV, 1990; CHEAH e LOOI, 1998) A transcrição do HPV inicia-se a partir de um mesmo promotor, que está localizado próximo ao gene E6, entre os diferentes tipos virais (PFISTER e FUCHS, 1994).

Atualmente já foram completamente descritos 118 tipos de HPV (DE VILLIERS et al., 2004). De acordo com as propriedades biológicas, os tipos de HPV dividem-se em dois grupos: cutâneotrófico e mucosatrófico. No grupo cutâneotrófico, encontra-se o HPV1, agente etiológico da verruga plantar, os HPVs 2 e 4 que causam as verrugas comuns, e cerca de 47 tipos virais associados a epidermodisplasia verruciforme (PFISTER, 2003). Por outro lado, no grupo mucosatrófico encontram-se mais de 40 tipos de HPV que infectam principalmente a superfície mucosa do trato genital e respiratório, dentre eles os tipos $6,11,16,18,31,33,45$ (DE VILLIERS, 1997).

\section{2 b) RELAÇÃO ENTRE HPV E AS LESÕES PROLIFERATIVAS DE LARINGE}

Vários estudos sugerem uma possível relação do HPV na etiopatogênese de tumores de cabeça e pescoço, incluindo cavidade oral, orofaringe e laringe em uma frequiência muito variável (TRAN, ROSE e O'BRIEN, 2007). Aproximadamente 25\% dos carcinomas de orofaringe têm apresentado infecção pelo HPV e as taxas de positividade em carcinomas orais têm variado de $4 \%$ a 31\% (HERRERO, 2003; SYRJANEN, 2005).

A relação do HPV com o carcinoma de laringe ainda não está bem estabelecida. Alguns autores associam o HPV como fator etiológico desta doença (JACOB et al., 2002; 
MORSHED et al., 2004) enquanto outros não concordam com essa associação (LINDEBERG, 1999).

Segundo Syrjänen e Surjänen (1981) a primeira evidência da associação entre o HPV e carcinoma de laringe surgiu pela detecção dos efeitos citopáticos típicos do HPV nestas lesões. O mesmo autor no ano seguinte confirmou a presença do HPV por imunoistoquímica para demonstrar a expressão de proteínas estruturais do vírus (SYRJÄNEN, SYRJÄNEN e PYRHÖNEN, 1982). Porém a mais convincente evidência do HPV em carcinomas de laringe deriva-se de estudos que demonstram DNA do vírus em lesões por diferentes métodos de hibridização e PCR, sendo encontrados principalmente os tipos de HPV de alto risco 16, 18, 31 e 33 (HERRERO, 2003; SYRJANEN, 2004).

Nos carcinomas de laringe as taxas de detecção do HPV variam entre 8 e $58.8 \%$, em função da sensibilidade e especificidade dos métodos moleculares de detecção viral (Southern blot, Hibridização in situ ou PCR) ou resultante de diferenças geográficas e populacionais (ALMADORI et al., 2001; GARCÍA-MILÍAN et al., 1998; ATULA et al., 1999; VENUTI et al.,2000; JACOB et al., 2002). Por métodos moleculares menos sensíveis, como a hibridização in situ, o DNA do HPV-16 foi detectado em 5 a $11 \%$ dos carcinomas de laringe (SYRJANEN, 1987; KAYA et al. 2001). Por outro lado quando a técnica de PCR é utilizada, a frequiência do HPV-16 nessas lesões malignas oscila entre 4 a 54\% (PEREZ-AYALA, 1990; TORRENTE et al. 2005). Parece altamente provável que a presença dos tipos de HPV de alto risco $(16,18,31$ e 33) é importante na etiologia de pelo menos alguns casos destas lesões (SYRJANEN, 2005).

A importância dos tipos de HPVs de baixo risco para o desenvolvimento de papilomas laríngeos está bem estabelecida e os tipos de HPV predominantemente presentes são os HPV 6 e/ou 11, os quais são os agentes etiológicos da papilomatose juvenil e adulta (VELYVYTE et al., 2002). Essa doença é caracterizada por múltiplos papilomas benignos que inicialmente crescem na corda vocal com subseqüente avanço para outras áreas do trato respiratório 
(KASHIMA et al, 1992). A transformação maligna pode ocorrer após longo decurso da papilomatose, entretanto é um evento raro, ocorrendo apenas em 3 a $7 \%$ dos pacientes e possivelmente associada à infecção por HPVs de baixo risco (GAYLIS e HAYDEN, 1991; LIE et al., 1994; GO, SCHWATRZ e DONOVAN, 2003).

As formas de transmissão do HPV no trato aéreo superior são algumas vezes especulativas. Adultos são na maioria das vezes infectados pelo contato com pessoas infectadas. Tem sido reconhecida que a papilomatose laríngea em crianças é causada por transmissão vertical, quando o recém nascido ao atravessar o canal vaginal entra em contato com fluido local contaminado (CASON, BEST e RAJU, 1999). Além disso, a transmissão orogenital é uma outra hipótese plausível e que explicaria a presença dos tipos anogenitais de HPV na orofaringe (ZUR HAUSEN, 1996).

\subsection{REGULADORES DO CICLO CELULAR}

As principais famílias de proteínas reguladoras que tem um papel importante no controle de progressão do ciclo celular são as ciclinas, quinases dependentes de ciclina (CDK), os inibidores de CDKs (CKI) e os produtos dos genes supressores de tumor: p53 e pRB . Duas famílias de inibidores de CDKs (CKIs) regulam negativamente o ciclo celular. Os

membros da família INK4, na qual incluem $\mathrm{p} 15^{\mathrm{INK} 4}, \mathrm{p} 16^{\mathrm{INK} 4}$, p18 e p19 especificamente se ligam a CDK4 e CDK6 e inibem sua associação com a ciclina D. Membros da família CIP/KIP, p2 ${ }^{\mathrm{CIP} 1}, \mathrm{p} 27^{\mathrm{KIP} 1}$ e p5 $7^{\mathrm{KIP} 2}$, também conhecidos como inibidores universais de CDK, inibem a atividade quinase de vários complexos de CDK. O produto do gene P53 é um importante regulador em ambas as fases $\mathrm{G} 1 / \mathrm{S}$ e $\mathrm{G} 2 / \mathrm{M}$ ativando p21, que é capaz inibir a formação do complexo ciclina/CDK e assim bloqueando o ciclo. Além de ativar a proteína 
p21, a p53 pode ativar Mdm2, uma proteína conhecida como regulador negativo de p53 (GOLIAS, CHARALABOPOULOS e CHARALABOPOULOS, 2004)

\section{3 a) A p53 E O CÂNCER}

Segundo Hardisson (2003) alterações do gene P53 são uma das anormalidades genéticas mais comuns em variados tipos de carcinomas, incluindo os de cabeça e pescoço. Este gene, no qual é localizado no cromossomo 17p13, tem uma relação importante na manutenção da integridade do genoma prevenindo a transformação oncogênica, e seu produto, a proteína p53, controla as funções essenciais da célula, associado à regulação do ciclo celular e apoptose (CABANILLAS et al, 2007).

Quando a célula é exposta a algum tipo de estresse genotóxico tais como dano no DNA e ativação de oncogenes, a proteína p53 se acumula rapidamente através de mecanismos póstranscricionais, o que leva a uma parada no ciclo celular para reparo do DNA danificado ou morte da célula por apoptose.

A inativação do gene P53, para Soussi e Lozano (2005), pode ser resultado de mutação, que ocorre em aproximadamente $50 \%$ dos tumores humanos. No câncer de laringe a perda da atividade de p53 por mutação é considerada um fenômeno comum, porém com um padrão diferente dos outros tipos de tumores de cabeça e pescoço (BOSCH et al, 2004).

Em neoplasias malignas, a alta expressão da proteína p53 foi observada, principalmente em carcinomas de tireóide (HORIE et al., 2001), nos carcinomas de esôfago (BAHNASSY et al., 2005) e carcinoma oral (YANAMOTO et al., 2002).

Um estudo realizado por Klatka (2001) demonstrou uma alta proporção de p53 (90\%) em carcinomas de laringe. Estes resultados confirmam observações anteriores de alta freqüência de p53 em carcinomas laríngeos (NADAL et al., 1995; PRUNERI et al., 1998). 
Dolcetti e colaboradores (1992) encontraram concordância na expressão de p53 entre tumores primários de laringe e metástases em linfonodos, o que sugere que alterações de p53 ocorrem em estágios iniciais da transformação maligna, porém não fornecem vantagens adicionais para a progressão neoplásica.

\section{3 b) A p27 E O CÂNCER}

A proteína p27, membro da família CIP/KIP, pode bloquear a progressão do ciclo celular inibindo especificamente a CDK2 pela ligação de ambos os complexos ciclina E CDK2 e ciclina A -CDK2. (LACY et al., 2004; BLOOM e PAGANO, 2003). Embora os níveis protéicos oscilem durante todo o ciclo celular, os níveis máximos dessa proteína são encontrados na fase de G1 e nas células quiescentes e em qualquer anormalidade durante o ciclo celular, essa proteína passa a exercer seu papel de supressora de tumor (BLOOM e PAGANO, 2003).

A presença de altos níveis de p27 é freqüentemente encontrada em lesões benignas (CHETTY, 2002). A alta expressão de p27 está relacionada à indução de proteção celular através da apoptose. (COQUERET, 2003). Assim, a perda da expressão de p27 impede o reparo de danos genômicos, favorecendo o processo de carcinogênese e resultando na progressão tumoral.

Deleções, metilações e aberrações proteolíticas podem acarretar uma diminuição da expressão de p27 (COQUERET, 2003). Nos tumores humanos são raras as mutações dessa proteína e estudos recentes demonstram a diminuição da expressão de p27 em diferentes tipos de tumores (SKOMEDAL et al., 1999; KIM et al., 2000; KHOO, 2002; KUO, 2002; HWANG et al., 2003). A baixa expressão de p27 pode ser indicativa de maior potencial metastático em carcinoma espinocelular de mucosa oral, podendo ser utilizado com um marcador do potencial 
de metástase nessas lesões (KUDO et al., 2005). No câncer bucal, a p27 é considerada um bom marcador, capaz de indicar a suscetibilidade do indivíduo em desenvolver lesões malignas, avaliar a sobrevida do paciente e estimar o potencial de recidiva dessas lesões (GUO-KANG et al., 1999; KUROPKAT et al., 2001).

Apenas um limitado número de autores tem investigado a relação de p27 em carcinomas de laringe (PIGNATARO et al., 2005). No câncer de laringe, a expressão diminuída de p27 parece estar associada à expansão do tumor e a estágios mais avançados da doença, sendo considerado um marcador de prognóstico (PRUNERI et al., 1999; HIRAI et al., 2003). Embora a expressão de p27 esteja relacionada com a diferenciação dos tumores de laringe, sua associação com metástase ainda não foi claramente definida (LIU et al., 2003).

\section{3 c) A Mdm2 E O CÂNCER}

Um dos alvos de ativação transcricional da proteína p53 é o oncogene homólogo humano murino duplo minuto (Mdm2). O Mdm2 é um oncogene cujo produto interage com a proteína supressora de tumor p53 e direciona essa proteína para a degradação proteassômica ubiquitina mediada (HONDA, TANAKA, YASUDA, 1997). A ligação Mdm2/p53 expõe um sinal de localização nuclear (NLS), existente na proteína Mdm2, permitindo o reconhecimento deste complexo protéico para exportação do núcleo para o citoplasma. No citoplasma, o complexo Mdm2/p53 é encaminhado para o proteassoma, onde Mdm2 tem função de ubiquitina-ligase, encaminhando a proteína p53 para degradação. Em seguida, Mdm2 fica livre para ser importada novamente para o núcleo (HARRIS e LEVINE, 2005). Assim, o controle de função de p53 é dependente dos estoques de Mdm2 e sua superexpressão poderá acarretar a perda de controle de ciclo celular na fase G1/S, contribuindo para a transformação maligna 
celular (MENDHELSON et al., 2001). O resultado é uma inibição da função da p53 a qual é necessária para que o ciclo celular seja interrompido e a célula encaminhada a apoptose (SOUZA, MESQUITA \& GOMES, 2000).

A amplificação ou alta expressão de Mdm2 comumente ocorre em tumores humanos, incluindo sarcomas de partes mole, osteosarcoma, rabidomiossarcoma, carcinoma oral, colorretal e mama, e melanomas. (FREEDMAN E LEVINE, 1999; ONEL e CORDONCARDO, 2004; ABDEL-FATTAH et al, 2000).

Em tumores de cabeça e pescoço, tais como carcinoma de laringe e de boca o aumento de expressão de Mdm2 parece estar associado à proliferação tumoral, podendo ser útil como marcador de transformação celular maligna (PRUNERI et al., 1997; LI et al, 2000).

Em alguns tumores, o gene Mdm2 pode apresentar-se pouco expresso, ocasionando uma baixa concentração de suas proteínas e dessa forma, permitindo a superexpressão do alelo mutante de p53. Portanto, o descontrole do Mdm2/p53 favorece a progressão maligna do tumor sem a intervenção de mecanismos de apoptose.

\subsection{HPV E OS REGULADORES DO CICLO CELULAR}

As oncoproteínas E6 e E7, codificadas pelo vírus HPV oncogênicos, induzem a transformação celular através da interação com inúmeras moléculas intracelulares, alterando a expressão de diversos genes. Possivelmente, os tumores infectados com HPV apresentam um background molecular diferente dos não infectados, o que pode ser ilustrado pelo fato de que o prognóstico de pacientes com tumores infectados com HPV pode ser diferente dos nãoinfectados (RITCHIE et al., 2003) e estão relacionadas com características avançadas da doença (SMITH et al., 2004). 
Há uma estreita correlação entre a presença do genoma viral de alto risco e mutações na seqüência gênica responsável pela transcrição e transdução da proteína p53, freqüentemente observada no câncer cervical primário (KIM, 1995), em lesões malignas orais (MAO, 1995) e nos tumores de laringe (ERDAMAR et al., 2002). Além disso, a proteína p53 está ligada à inativação de fatores de crescimento celular, como a proteína p21, PCNA (Proliferating Cell Nuclear Antigen) e Ki-67. Assim, as oncoproteínas E6 e E7 estão envolvidas com a degradação da proteína p53 que passa a não mais exercer sua função inibitória sobre proteínas que controlam a divisão da célula, também colaborando com a proliferação celular desordenada (SCULLY, FIELD e TANZAWA, 2000). Portanto, a inativação de p53 parece representar o fator mais importante na progressão de malignidade, possivelmente por não conseguir impedir diretamente a imortalização e transformação celular. A maioria dos genes supressores de oncogenes participa diretamente na regulação dos eventos de sinalização, estimulando a progressão do ciclo celular e/ou a morte celular. Qualquer erro no controle de reparo dos eventuais pontos de mutação ocorridos durante o ciclo, células são normalmente encaminhadas para apoptose (MURAKAMI e WOUDE, 2001). Portanto, desregulação combinada nos eventos celulares de controle e ou apoptose levam a transformação celular maligna: o câncer.

A maior expressão de Mdm2 e p27 no câncer cervical parece não estar associada à presença de HPV de alto risco (TRONCONE et al., 1998). Entretanto, a associação da expressão de p27 e Mdm2 e a infecção pelo HPV nas lesões de laringe ainda não foi devidamente abordada para a avaliação da eventual desregulação funcional dessa proteína supressora de tumor ocasionada pelo HPV. 
1) Verificar a presença do HPV em carcinomas epidermóides invasivos de laringe com e sem metástases através da detecção e identificação dos tipos de HPV de baixo ou alto risco (6, $11,16,18,31$ e 33$)$.

2) Avaliar a expressão das proteínas p53, p27 e Mdm2 como possíveis marcadores de metástase em carcinomas epidermóides invasivos de laringe.

3) Verificar se existe associação entre HPV e expressão imunoistoquímica de p53, p27 e Mdm2 em carcinomas epidermóides invasivos de laringe com e sem metástase. 


\subsection{ASPECTOS ÉTICOS}

O presente estudo foi analisado pelo Comitê de Ética em Pesquisa de Experimentação Humana da Faculdade de Medicina de Ribeirão Preto da Universidade de São Paulo (USP), e enquadrado como APROVADO, de acordo com o Processo n. 12206/2004 (Anexo A).

\subsection{CASUÍSTICA}

Biópsias de 54 pacientes foram selecionadas, de acordo com o diagnóstico histológico de carcinoma invasor de laringe e subdivididos em dois grupos, segundo a presença ou ausência de metástases em linfonodos. Destes, 27 pacientes apresentavam carcinoma invasor de laringe com metástases e outros 27 pacientes apresentavam carcinoma invasor de laringe sem metástase. Nos pacientes com metástase, foram avaliados cortes da lesão primária e de metástases respectivos linfonodos. Informações clínico-patológicas tais como idade, sexo, história de tabagismo e consumo de álcool foram coletadas dos laudos obtidos do serviço de prontuários, SAME (Serviço de Arquivo Médico) do Hospital das Clínicas de Ribeirão Preto (USP). Os blocos de parafina foram selecionados retrospectivamente (1995 - 2004) do arquivo de Serviço de Patologia (SERPAT) do HCFMRP-USP. Em seguida, cortes histológicos corados em hematoxilina-eosina, pertencentes ao arquivo de lâminas do serviço citado, foram reavaliados por patologista experiente. Todas as biópsias foram submetidas a novos cortes histológicos de $5 \mu \mathrm{m}$ de espessura, os quais foram colocados em lâminas previamente silanizadas com organosilano $4 \%$ em acetona e submetidas ao método de imunoistoquímica para avaliação das proteínas p53, p27 e Mdm2. Adicionalmente, outros cortes histológicos da mesma biópsia, com espessura de $10 \mu \mathrm{m}$, foram utilizados para os procedimentos de extração de DNA, detecção e identificação dos tipos de HPV 6, 11, 16, 18, 31 e 33. 


\subsection{REAÇÃO DE IMUNOISTOQUÍMICA}

Para detecção das proteínas p53, p27 e Mdm2 as reações de imunoistoquímica foram realizadas utilizando o método de imunoperoxidase (Novostain, Novocastra, Newcastle, UK). Os cortes foram desidratados em xilol, reidratados em graduação alcoólica crescente e enxaguados em água. Para inibição da atividade da peroxidase endógena presente nos tecidos, as lâminas foram imersas em citrato de sódio tamponado $10 \mu \mathrm{m}, \mathrm{pH}$ 6,0, e fervidos em panela a vapor na temperatura de $95^{\circ}$ a $99^{\circ}$ por 40 minutos. Para inibir a peroxidase endógena, os cortes foram tratados com peróxido de hidrogênio a 3\% por 20 minutos. A seguir, os cortes foram lavados três vezes com PBS e incubados com soro de cavalo por 30 minutos. Posteriormente os cortes foram incubados com anticorpo primário contra p53 (diluído 1:400, DAKO Gostrup, Denmark), p27 $7^{\mathrm{KIP} 1}$ (diluído 1:50, Novocastra, Newcastle, Tyne, United Kingdom) e Mdm2 Ab-1 (clone SMP14, diluído 1:100, Freemont, CA, USA) em câmara úmida temperatura ambiente overnight. Após a incubação com o anticorpo primário, as lâminas foram lavadas três vezes em PBS, incubadas, consecutivamente, com anticorpo secundário biotinilado (LSAB, DAKO, Glostrup, Dinamarca) e complexo estreptavidinabiotina-peroxidase (LSAB, DAKO), a $37^{\circ} \mathrm{C}$ por 30 minutos a cada incubação. Entre cada um dos procedimentos acima, as lâminas foram cuidadosamente lavadas três vezes em solução de PBS. Subsequentemente as lâminas foram incubadas em solução contendo $5 \mathrm{mg}$ de diaminobenzidina (DAB, GIBBICO, Gaithersburg, Maryland, USA), dissolvida em 5ml de PBS e $100 \mu 1$ desta solução foi utilizada. A reação foi bloqueada com uma lavagem em PBS, seguida por lavagem com água destilada. Depois as lâminas foram levemente contracoradas com hematoxilina de Harris por 60 segundos para p53, p27 e Mdm2 e lavados em água corrente. A seguir foram reidratadas em três soluções de álcool absoluto, seguidas de duas imersões em xilol e montadas com Permount (MERCK, Darmstadt, Alemanha). 


\section{3 a) Controles}

Dois controles foram incluídos para cada reação e para todas as proteínas avaliadas: positivo e negativo. Os controles positivos foram cortes histológicos de carcinoma mamário (p53), carcinoma invasor de laringe (p27) e amígdala humana normal (Mdm2). Os controles negativos foram os mesmos tecidos humanos, apenas omitindo-se a etapa de incubação com anticorpo primário.

3.3 b) Aquisição das Imagens e Análise Quantitativa de p53, p27 e Mdm2

Após a reação de imunoistoquímica a imunomarcação de p53, p27 e Mdm2 foi avaliada por patologista experiente e classificada como marcação negativa, leve, moderada e intensa. Os núcleos (p53 e p27) ou citoplasma (Mdm2) positivos foram automaticamente quantificados pelo equipamento Image-Pro Plus (Cybernetics, MD, EUA) o qual inclui um microscópio, uma câmera digital e um software para análise de imagem. Em média, oito campos randômicos do microscópio foram selecionados para a análise de 1000 células marcadas (núcleo ou citoplasma) por biópsia em todos os pacientes. A aquisição da imagem das lâminas dos 54 pacientes com carcinoma de laringe (com e sem metástase) e dos linfonodos cervicais foi realizada por fotomicrografia e a imagem processada pelo software. Cada lâmina foi digitalizada e a segmentação foi controlada pelo filtro RGB existente no programa de análise de imagem. A contagem automática das células positivas foi estabelecida e expressa em porcentagem. As análises quantitativas de p53, p27 e Mdm2 foram classificadas como negativas quando os níveis das proteínas apresentavam-se insignificantes $(<10 \%)$ ou positivas com valores acima do cut-off (10\%), como proposto por Yanamoto e colaboradores, 2002. 


\subsection{DETECÇÃO E TIPAGEM DO HPV}

\section{4 a) Extração de DNA genômico de tecido parafinizado}

Dois cortes histológicos de tecido parafinizado, com $15 \mu \mathrm{m}$ de espessura foram transferidos para eppendorfs estéreis, adicionados de $1000 \mu 1$ de xilol absoluto em cada tubo. O tecido parafinizado contendo xilol foi homogeneizado por inversão e incubado em banho maria a $56^{\circ} \mathrm{C}$, por $10 \mathrm{~min}$ seguido de centrifugação $12.000 \mathrm{rpm}$ por $2 \mathrm{~min}$. O sobrenadante foi descartado e esse procedimento foi repetido por 3 a 5 vezes para retirada completa da parafina. Na última centrifugação, o sobrenadante foi removido, adicionaram-se $750 \mu 1$ de xilol absoluto e $250 \mu 1$ de etanol absoluto, e, em seguida, a amostra foi homogeneizada, centrifugada a 12.000 rpm por 2 min e, novamente o sobrenadante descartado. Em seguida, foram adicionados ao sedimento, $500 \mu 1$ de xilol e $500 \mu 1$ de etanol absoluto, seguido de centrifugação e descarte do sobrenadante. Novamente, foram adicionados $250 \mu \mathrm{l}$ de xilol e $750 \mu \mathrm{l}$ de etanol absoluto. $\mathrm{Na}$ seqüência, $500 \mu 1$ de etanol absoluto foram acrescidos ao sedimento centrifugando e novamente descartando o sobrenadante, sendo realizado por 2 vezes. No sedimento obtido foi adicionado 1 ml de tampão de lise Tris-HCL 10 Mm, pH 8,5 (2,5 mM MgCL2, 50 mM KCL, Nonidet P-40 $1 \%$ e Tween 1\%). Em seguida, os tubos foram homogeneizados, centrifugados a $12.000 \mathrm{rpm}$, por 2 min e o sobrenadante descartado. Novamente, o sedimento obtido foi ressuspenso com $100 \mu \mathrm{l}$ de tampão de lise Tris-HCL $10 \mathrm{mM}(\mathrm{pH} \mathrm{8,5)} \mathrm{e} 10 \mu \mathrm{l}$ de proteinase $\mathrm{K}(10 \mathrm{mg} / \mathrm{ml})$ e incubado em banho maria a $65^{\circ} \mathrm{C}$ overnight. Após o período de incubação, os tubos foram submetidos à temperatura de $94^{\circ} \mathrm{C}$ por 10 min objetivando a inativação da proteinase $\mathrm{K}$. $\mathrm{O}$ DNA extraído foi acondicionado a $-20^{\circ} \mathrm{C}$ até o momento dos experimentos de amplificação para a detecção do HPV. 
3.4 b) Amplificação do HPV (região consenso) e do gene de betaglobina

Após a extração, o DNA obtido dos tecidos parafinados foi amplificado por PCR, usando 20mM de dNTP, $10 \mathrm{mM}$ de cada primer, 5U Taq DNA polimerase (Invitrogen, EUA), 3,5 $\mu \mathrm{L}$ de 10X enzima tamponada, $20 \mu \mathrm{g}$ do DNA genômico (50ng), e água destilada deionizada para completar o volume total de $25 \mu \mathrm{L}$. O DNA foi amplificado em termociclador (MJ Research, MA, USA) de acordo com as seguintes condições de ciclo: 1 ciclo de $94^{\circ} \mathrm{C}$ por $7 \mathrm{~min}, 37$ ciclos consecutivos de $94^{\circ} \mathrm{C}$ por $30 \mathrm{~s}, 45^{\circ} \mathrm{C}$ por $45 \mathrm{~s}$ e $72^{\circ} \mathrm{C}$ por 1 min. Finalmente 1 ciclo de $72^{\circ} \mathrm{C}$ por 10 min, e então o DNA amplificado foi mantido a $4{ }^{\circ} \mathrm{C}$ indefinidamente. Visto que os DNA extraídos de tecido fixados em formalina tamponada e incluídos em parafina são bastante fragmentados, foram os primers: GP5+ e GP6+ (Ting et al., 1990) que amplificam pequenos fragmentos (150pb). O produto amplificado foi aplicado em gel de poliacrilamida $10 \%$ não desnaturante e submetido à eletroforese em 200 volts por 1 hora e 15 minutos.

A amplificação do gene de betaglobina foi utilizada para avaliação da integridade do DNA genômico pós-extração e como um controle interno da amplificação. A mistura de reação foi constituída de: $2,5 \mu \mathrm{L}$ de tampão da enzima $10 \mathrm{X}, 0,75 \mu \mathrm{L}$ de $\mathrm{MgCl} 250 \mathrm{mM}, 0,25 \mu \mathrm{L}$ de dNTP 20mM, 0,5 $\mu \mathrm{L}$ do primer de betaglobina ( $0,25 \mu \mathrm{L}$ PCO4 $10 \mu \mathrm{M}$ e $0,25 \mu \mathrm{L}$ do primer PCO3 $10 \mu \mathrm{M}), 0,25 \mu \mathrm{L}$ de Taq DNA polimerase 500U e 1,0 $\mu \mathrm{L}$ de DNA a $100 \mathrm{ng} / \mu \mathrm{L}$. O volume final da reação foi de $25 \mu \mathrm{L}$. Os ciclos da reação foram estabelecidos segundo Iwasawa e colaboradores (1997) e modificados posteriormente nas etapas de padronização. Assim, o DNA a ser amplificado e demais reagentes de amplificação foram submetidos à desnaturação inicial $\left(94^{\circ} \mathrm{C}-7\right.$ minutos), seguido de 35 ciclos subseqüentes de desnaturação $\left(94^{\circ} \mathrm{C}-1\right.$ minuto), hibridização $\left(55^{\circ} \mathrm{C}-1\right.$ minuto), extensão $\left(72^{\circ} \mathrm{C}-1\right.$ minuto) e extensão final em temperatura de $72^{\circ} \mathrm{C}$ por 10 minutos. 
3.4 c) Amplificação com primers tipo específicos (HPV 6, HPV 11, HPV 16, HPV 18, HPV 31 e HPV 33)

Para a tipificação viral utilizamos pares de primers específicos HPV16E7.667/ HPV16E7.774 para o HPV16 e HPV18R7.696/HPV18E7.799 para HPV18, descritos por Walboomers e colaboradores (1999) que amplificam fragmentos de aproximadamente 100pb da região E7 dos DNAs virais. Para os tipos de HPV6, HPV11, HPV31 e HPV33 utilizamos respectivamente os seguintes primers: HPV65'/HPV63', HPV115'/HPV113', HPV31e7.811/HPV31E7.890 e HPV33E7.671/HPV33E7.671. Para identificar os tipos de HPV18 e HPV31 utilizamos o kit PCR Master Mix M7502 (Promega) cuja solução pronta para uso contém Taq polimerase, dNTPs, MgCL2 e um tampão com uma concentração adequada para melhor amplificação do DNA.

O DNA amplificado foi aplicado em gel de poliacrilamida a $10 \%$ não desnaturante à eletroforese em 200 volts por 1 hora e 45 minutos, sendo posteriormente corado pelo protocolo segundo o método de Sanguinetti e colaboradores (1994).

\subsection{ANÁLISE ESTATÍSTICA}

O Teste Exato de Fisher e Teste T de Student foram utilizados para comparação entre os diferentes parâmetros clínicos (idade, sexo, consumo de álcool e fumo) nos 54 pacientes com carcinoma invasivo de laringe com e sem metástases.

Testes não-paramétricos foram empregados nas analises quantitativas, uma vez que os dados da proteína p53 não apresentaram distribuição normal. O teste não paramétrico de Mann-Whitney foi aplicado para comparar a expressão quantitativa das proteínas p53, p27 e Mdm2 entre os dois grupos de neoplasias malignas de laringe (carcinoma invasivo sem 
metástase e carcinoma invasivo com metástase). Teste de Wilcoxon foi aplicado para comparar a expressão quantitativa de p53, p27 e Mdm2 entre carcinomas invasivos com metástase e seus linfonodos cervicais. Para a análise de correlação entre diferentes proteínas em cada tipo de lesão e entre carcinomas invasivos com metástase e as biópsias de linfonodos cervicais, foi empregado o coeficiente de correlação para postos de Spearman, por meio do software GraphPad Instat (San Diego, CA, USA).

Foram considerados estatisticamente significantes os valores de $\mathrm{p}<0,05$. 
RESULTADOS 


\subsection{CÂNCER DE LARINGE E PARÂMETROS CLÍNICOS}

Os parâmetros clínicos (Tabela 1) demonstram que sexo, consumo de cigarros, consumo de álcool e idade foram relativamente homogêneos em ambos os grupos de carcinoma de laringe com e sem metástase. Não houve diferença estatisticamente significante entre os dois grupos de carcinomas quanto aos parâmetros clínicos analisados.

Tabela 1. Comparação entre 54 pacientes com carcinoma invasivo de laringe sem metástase $\left(\right.$ LSCC $\left.^{\mathrm{WT}}\right)$ e com metástase (LSCC ${ }^{\mathrm{W}}$ ) em linfonodos cervicais, agrupados de acordo com sexo, consumo de álcool, fumo e idade.

\begin{tabular}{lcccccc}
\hline & Sexo & \multicolumn{2}{c}{ tabagismo } & \multicolumn{2}{r}{ etilismo } & Idade \\
\hline M. & F. & Sim Não & Sim & Não & M \pm D.P.
\end{tabular}

\begin{tabular}{|c|c|c|c|c|c|c|c|}
\hline $\begin{array}{l}\text { Carcinoma invasivo de laringe } \\
\text { sem metástase }\left(\mathrm{LSCC}^{\mathrm{WT}}\right)\end{array}$ & 18 & 9 & 23 & 3 & 15 & 11 & $59,185 \pm 7,661$ \\
\hline $\begin{array}{l}\text { Carcinoma invasivo de laringe } \\
\text { com metástase }\left(\mathrm{LSCC}^{\mathrm{W}}\right)\end{array}$ & 22 & 5 & 24 & 2 & 18 & 8 & $56,037 \pm 9,646$ \\
\hline Comparações & \multirow{2}{*}{\multicolumn{2}{|c|}{$\begin{array}{l}p \text {-valor }^{\text {a }} \\
p=0,3520\end{array}$}} & \multirow{2}{*}{\multicolumn{2}{|c|}{$\begin{array}{l}\text { p-valor }{ }^{\mathbf{a}} \\
\mathrm{p}=1,0000\end{array}$}} & \multirow{2}{*}{\multicolumn{2}{|c|}{$\begin{array}{l}\text { p-valor } \\
\mathbf{a}^{\mathbf{a}} \\
\mathrm{p}=0,5653\end{array}$}} & p-valor ${ }^{b}$ \\
\hline $\mathrm{LSCC}^{\mathrm{WT}}$ vs. $\operatorname{LSCC}^{\mathrm{W}}$ & & & & & & & $\mathrm{p}=0,1900$ \\
\hline
\end{tabular}

$\mathbf{M}=$ Masculino; $\mathbf{F}=$ Feminino; $\mathbf{M}=$ Média; D.P.= Desvio Padrão

a: Fisher's exact test

b: Student t-test 


\subsection{DETECÇÃO E TIPAGEM DO HPV}

Em relação à infecção pelo HPV o DNA viral foi detectado em 4/54 $(7,4 \%)$ pacientes com câncer invasivo de laringe, sendo que 02 pacientes pertenciam ao grupo de carcinoma de laringe sem metástase (LSCC ${ }^{\mathrm{WT}}$ ) e 02 pertenciam ao grupo de carcinomas de laringe com metástase $\left(\mathrm{LSCC}^{\mathrm{W}}\right)$. Dentre os pacientes HPV positivos, HPV6 e HPV 31 foram detectados respectivamente em 01 paciente no grupo de carcinoma de laringe sem metástase e em 01 paciente pertencente ao grupo com metástase. Nos outros 02 pacientes apareceram as associações HPV 31 e 33 e HPV 6 e 16 (Tabela 2). Também foram pesquisados, porém não encontrados em nenhuma biópsia de carcinoma de laringe os tipos HPV 11 e 18.

Tabela 2. Tipagem do HPV em pacientes com carcinoma invasivo de laringe sem metástase $\left(\mathrm{LSCC}^{\mathrm{WT}}\right)$ e com metástase $\left(\mathrm{LSCC}^{\mathrm{W}}\right)$ em linfonodos cervicais.

\begin{tabular}{ccccc}
\hline & \multicolumn{3}{c}{ LSCC $^{W T}$} & \multicolumn{2}{c}{ LSCC $^{W}$} \\
\hline Tipos de HPV & Paciente 1 & Paciente 2 & Paciente 3 & Paciente 4 \\
\hline HPV6 & $\mathrm{X}$ & - & - & $\mathrm{X}$ \\
\hline HPV11 & - & - & - & - \\
\hline HPV16 & - & - & - & $\mathrm{X}$ \\
\hline HPV18 & - & - & - & - \\
\hline HPV31 & - & $\mathrm{X}$ & $\mathrm{X}$ & - \\
\hline HPV33 & - & $\mathrm{X}$ & - & - \\
\hline
\end{tabular}




\subsection{CARCINOMA INVASIVO DE LARINGE E EXPRESSÃO IMUNOISTOQUÍMICA} p53, p27 e Mdm2

A imunomarcação de p53, p27 e Mdm2 foi classificada negativo, leve, moderada e intensa como mostra a tabela 3 .

Tabela 3. Distribuição da intensidade de marcação de p53, p27 e Mdm2 em carcinoma invasivo de laringe com metástase $\left(\mathrm{LSCC}^{\mathrm{W}}\right)$ e sem metástase $\left(\mathrm{LSCC}^{\mathrm{Wt}}\right)$ em linfonodos cervicais, assim como biópsias de linfonodos cervicais com metástase (LB)

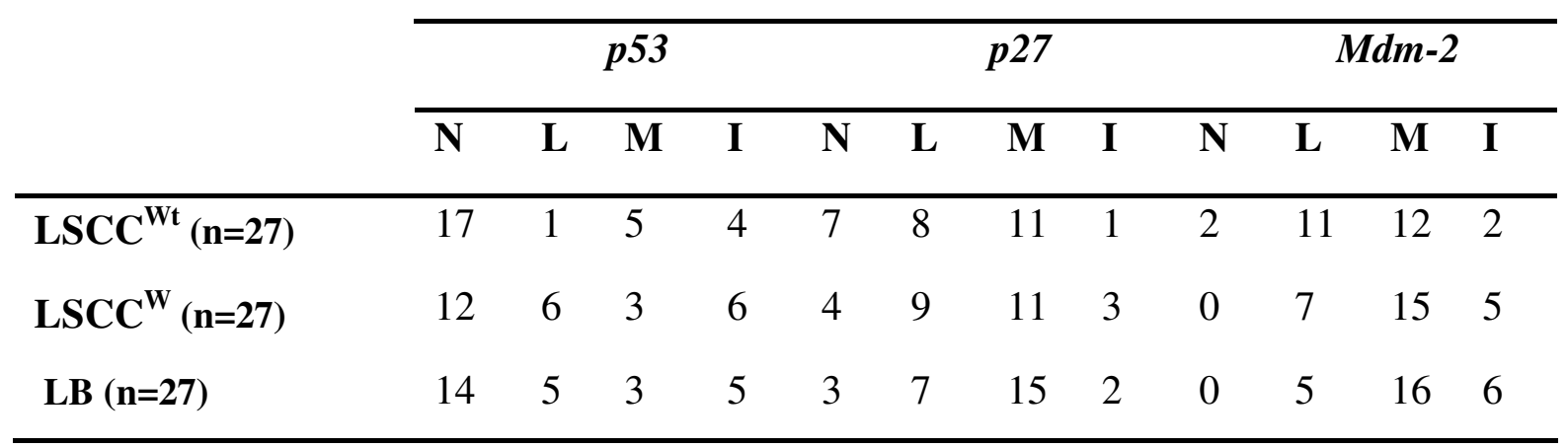

$\mathbf{N}=$ negativo; $\mathbf{L}=$ leve; $\mathbf{M}=$ moderada $; \mathbf{I}=$ intensa;

$\mathbf{L S C C}^{\mathbf{W}}=$ Carcinoma invasivo de laringe com metástase em linfonodos cervicais

$\mathbf{L S C C}^{\mathbf{W T}}=$ Carcinoma invasivo de laringe sem metástase

$\mathbf{L B}=$ Linfonodos cervicais

A partir desta análise qualitativa somente as lesões que foram classificadas como leve, moderada e intensa marcação foram quantificadas.

A figura 1 mostra exemplos de marcação intensa nos casos examinados.

A expressão imunoistoquímica quantitativa de p53, p27 e Mdm2 está presente na tabela 4 . 


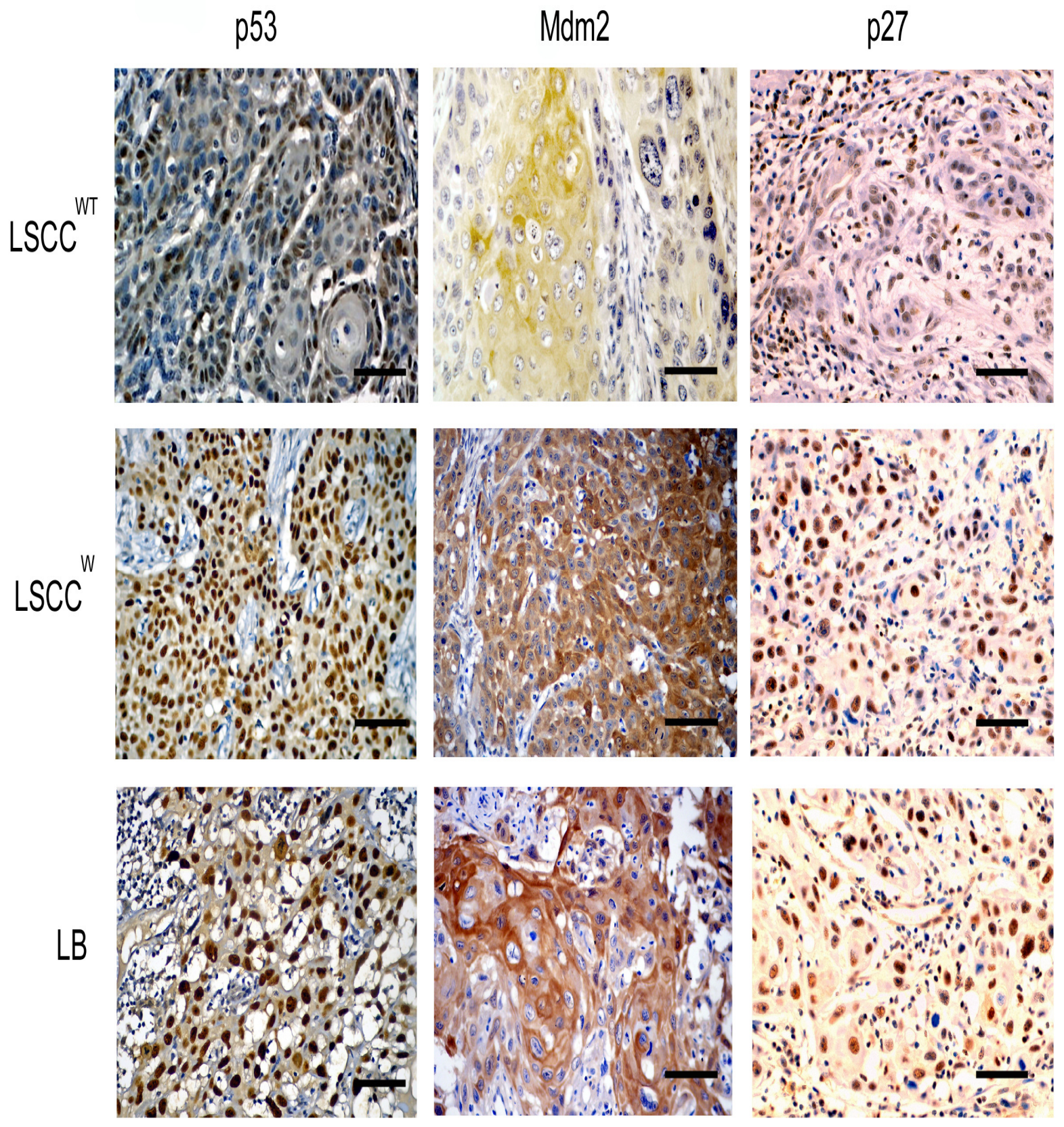

Figura 1. Expressão imunoistoquímica de p53, p27 e Mdm2 em carcinomas invasivos de laringe sem metástase $\left(\operatorname{LSCC}^{\mathrm{WT}}\right)$, com metástase $\left(\mathrm{LSCC}^{\mathrm{W}}\right)$ e nos linfonodos cervicais (LB). 
Tabela 4. Expressão imunoistoquímica quantitativa do p53, p27 e Mdm2 de acordo com o diagnóstico histológico e expresso por Média (M) e Desvio Padrão (DP).

\begin{tabular}{|c|c|c|c|}
\hline & \\
\hline & $p 53^{a}$ & $p 27^{b}$ & $\operatorname{Mdm} 2^{c}$ \\
\hline & $\mathbf{M} \pm \mathbf{D P}$ & $\mathbf{M} \pm \mathbf{D P}$ & $\mathbf{M} \pm \mathbf{D P}$ \\
\hline $\operatorname{LSCC}^{\mathrm{Wt}}(\mathrm{n}=27)$ & $28,141 \pm 38,332$ & $54,148 \pm 35,106$ & $61,952 \pm 27,910$ \\
\hline $\operatorname{LSCC}^{\mathrm{W}}(\mathrm{n}=27)$ & $38,144 \pm 38,508$ & $58,804 \pm 29,713$ & $72,826 \pm 20,188$ \\
\hline Comparações & $p^{a}$ & $p^{b}$ & $p^{\mathrm{c}}$ \\
\hline $\operatorname{LSCC}^{\mathrm{WT}}$ vs. LSCC $^{\mathrm{W}}$ & $\mathrm{p}=0,3197$ & $\mathrm{p}=0,8490$ & $\mathrm{p}=0,1945$ \\
\hline
\end{tabular}

$\mathbf{L S C C}^{\mathrm{W}}$ = Carcinoma invasivo de laringe com metástase em linfonodos cervicais;

$\mathbf{L S C C}^{\mathbf{W t}}=$ Carcinoma invasivo de laringe sem metástase;

${ }^{a, b, c}$ Mann-Whitney $=p>0,05$.

Tanto no grupo de carcinomas de laringe sem metástase (LSCC ${ }^{\mathrm{WT}}$ ) quanto no grupo de laringe com metástase $\left(\mathrm{LSCC}^{\mathrm{WT}}\right.$ ) observou-se alta expressão de p53, p27 e Mdm2. Entretanto, a avaliação da expressão de todas as proteínas entre os grupos $\operatorname{LSCC}^{\mathrm{WT}}$ e $\operatorname{LSCC}^{\mathrm{W}}$ não demonstrou diferença estatisticamente significante.

Como esperado, níveis similares de todas as proteínas foram verificados entre $\mathrm{LSCC}^{\mathrm{W}} \mathrm{e}$ linfonodos cervicais com metástase (LB), revelando correlação positiva de p53 (p<0,0001, r = 0,8036), $\mathrm{p} 27(\mathrm{p}=0,0059, \mathrm{r}=0,4777)$ e Mdm2 ( $\mathrm{p}=0,0022, \mathrm{r}=0,5312)$ em lesões de laringe e metástases em linfonodos (Tabela 5). 
Tabela 5. Comparação entre expressão quantitativa de p53, p27 e Mdm2 em carcinomas de laringe invasivos com metástases e seus respectivos linfonodos cervicais.

\begin{tabular}{cccc}
\hline & p53 & p27 & Mdm2 \\
\hline LSCC $^{\mathbf{W}}(\mathbf{n = 2 7})$ & $38,144 \pm 38,508$ & $58,804 \pm 29,713$ & $72,826 \pm 20,188$ \\
$\mathbf{L B}(\mathbf{n = 2 7})$ & $29,567 \pm 36,587$ & $61,933 \pm 29,318$ & $69,704 \pm 20,711$ \\
\hline Teste de Wilcoxon & $p=0,1205$ & $p=0,2469$ & $p=0,3997$ \\
Teste de Correlação de & $r=0,8036$ & $r=0,4777$ & $r=0,5312$ \\
Spearman & $p<0,0001$ & $p=0,0059$ & $p=0,0022$ \\
\hline
\end{tabular}

$\mathbf{L S C C}^{\mathrm{W}}=$ Carcinoma invasivo de laringe com metástase em linfonodos cervicais;

$\mathbf{L B}=$ Linfonodos cervicais

Para a análise de correlação entre diferentes proteínas em cada tipo de lesão foi empregado o coeficiente de correlação para postos de Spearman como mostra a tabela 6.

Tabela 6. Análise de correlação entre expressão quantitativa de p53, p27 e Mdm2, pareados dois a dois, entre os diferentes tipos de lesões.

\begin{tabular}{lccc}
\hline & p53 vs. p27 & p53 vs. MDM2 & p27 vs. MDM2 \\
\hline $\mathbf{L S C C}^{\mathbf{W t}}(\mathbf{n = 2 7 )}$ & $r=-0,0540$ & $r=-0,2589$ & $r=0,3800$ \\
& $p=0,7891$ & $p=0,1921$ & $p=0,0506$ \\
\hline \multirow{2}{*}{$\operatorname{LSCC}^{\mathbf{W}}(\mathbf{n = 2 7 )}$} & $r=-0,1114$ & $r=0,3787$ & $r=0,0006$ \\
& $p=0,5801$ & $p=0,0514$ & $p=0,9976$ \\
\hline \multirow{2}{*}{$\mathbf{L B}(\mathbf{n}=\mathbf{2 7})$} & $r=-0,1503$ & $r=0,2351$ & $r=-0,1445$ \\
& $p=0,4543$ & $p=0,2379$ & $p=0,4720$ \\
\hline
\end{tabular}

De acordo com a tabela acima, nenhum dos coeficientes calculados se mostrou significante. 


\subsection{TIPOS DE HPV E EXPRESSÃO IMUNOISTOQUÍMICA DE p53, p27 e Mdm2}

A expressão de p53 foi negativa em todos os pacientes com câncer de laringe HPV positivos. Alta expressão de p27 foi observada em $3(75 \%)$ de 4 pacientes, com uma média de $51,7 \%$ de células marcadas (Tabela 7). Por outro lado a proteína Mdm2 teve uma alta expressão em todos os pacientes demonstrando um percentual médio de $66.1 \%$. Entretanto, no grupo de carcinomas de laringe HPV negativos altos níveis de p53, p27 e Mdm2 foram observados.

Dentre os tipos de HPV relacionados observou-se uma variação da expressão de p27 e Mdm2 de 0 a $92,7 \%$ e de 13,6 a $91,8 \%$, respectivamente.

Tabela 7. Expressão quantitativa de p53, p27 e Mdm2 relacionada ao tipo de HPV em carcinomas invasivos de laringe.

\begin{tabular}{ccc}
\hline $\mathbf{p 5 3}(\%)$ & $\mathbf{p 2 7}(\%)$ & Mdm2(\%) \\
\hline Média \pm DP & Média \pm DP & Média \pm DP \\
\hline $0,0 \pm 0,0$ & $51,7 \pm 38,6$ & $66,1 \pm 36,1$ \\
$35,8 \pm 38,7$ & $56,9 \pm 32,2$ & $67,5 \pm 24,1$ \\
$0,0 \pm 0,0$ & $51,5 \pm 0,0$ & $91,8 \pm 0,0$ \\
$0,0 \pm 0,0$ & $62,7 \pm 0,0$ & $13,6 \pm 0,0$ \\
$0,0 \pm 0,0$ & $0,0 \pm 0,0$ & $71,6 \pm 0,0$ \\
$0,0 \pm 0,0$ & $92,7 \pm 0,0$ & $87,7 \pm 0,0$ \\
\hline
\end{tabular}

DP : Desvio Padrão 


\section{- quanto ao câncer de laringe e parâmetros clínicos}

O desenvolvimento de neoplasias epiteliais do trato aéreo superior é considerado um fenômeno complexo devido à multiplicidade de agentes carcinógenos colaboradores para a transformação celular neste sítio. O fumo e o álcool são os mais importantes fatores de risco para o desenvolvimento de carcinomas de cabeça e pescoço sendo que a ação combinada entre eles pode multiplicar os riscos para a doença (DIKSHIT et al, 2005; TALAMINI et al, 2002). É notável que pacientes não fumantes com câncer de laringe apresentem um melhor curso clínico da doença quando comparado à pacientes fumantes. Um estudo realizado por Agudelo e colaboradores (1997) mostrou que em pacientes sem história prévia de consumo de álcool e cigarros, as lesões poderiam se desenvolver mais tardiamente.

No presente estudo, observamos que a maioria dos pacientes com carcinoma de laringe com e sem metástase relataram consumo de álcool e cigarros, porém não houve diferença estatisticamente significante entre os dois grupos de carcinomas quanto às características analisadas.

A média de idade dos pacientes com câncer de laringe encontrada no presente estudo varia entre 56 e 59 anos. Esta média apresenta-se dentro do intervalo de idade relatado por Goiato e colaboradores (2006), onde os 88 pacientes estudados com câncer de laringe encontravam-se na faixa etária de 51 a 69 anos. Muscat e colaboradores. (1995) conduziram um estudo em Nova Iorque e afirmaram que o grupo etário predominante encontra-se acima dos 40 anos de idade. Outros estudos epidemiológicos seriam necessários para compreendermos a aparente preferência do câncer de laringe por indivíduos de meia idade.

Quanto ao sexo dos pacientes, observam-se em ambos os grupos uma maior predominância para o sexo masculino. Pode-se relacionar o achado ao maior número de homens expostos a antecedentes relativos ao fumo e consumo de álcool. 


\section{- quanto à detecção e tipagem do HPV}

Numerosos estudos até então publicados não nos permitem definir com precisão qual o possível papel do HPV na carcinogênese laríngea. Utilizando a técnica de hibridização in situ, Brito e colaboradores (2000) encontraram DNA do HPV em 4/45(8,8\%) de casos de carcinoma invasivo de laringe. Utilizando a técnica de Southern blot, Scheurlen e colaboradores (1986) detectaram 3\% de positividade para HPV enquanto Watts e colaboradores (1991) detectou o vírus em 11\% dos casos. Garcia Mílian e colaboradores (1998) utilizando a técnica de PCR encontraram o HPV em 48,5\% das amostras. No presente estudo o HPV foi detectado por método de PCR em 7,4\% dos casos de carcinomas de laringe. Esta discrepância pode ser atribuída à variação da sensibilidade dos métodos empregados, bem como à diversidade das populações estudadas.

- quanto ao carcinoma invasivo de laringe e a expressão imunoistoquímica de p53, p27 e $\operatorname{Mdm} 2$

De acordo com Kaskayasi e colaboradores (2001) tem-se investigado uma série de proteínas com o objetivo de se encontrar novos marcadores que possam ser utilizados como parâmetros para predizer a evolução das lesões de laringe.

Segundo Bartkova e colaboradores (1995) o processo de carcinogênese na laringe é baseado no acúmulo de vários estágios de danos genéticos, que frequentemente afetam genes envolvidos na regulação do ciclo celular. $\mathrm{Na}$ análise apresentada na tabela 4, as proteínas p53, p27 e Mdm2 foram avaliadas para verificar a possibilidade de serem bons marcadores de metástase em carcinomas de laringe. Observamos uma alta expressão de p53, p27 e Mdm2 em $\mathrm{LSCC}^{\mathrm{W}}$ e LSCC ${ }^{\mathrm{WT}}$, e não houve diferença estatisticamente significante ao comparar as lesões para cada proteína. Além disso, podemos considerar os valores percentuais de p53, p27 e 
Mdm2 aproximadamente constantes para as $\operatorname{LSCC}^{\mathrm{W}}$ e $\mathrm{LSCC}^{\mathrm{WT}}$, uma vez que eles apresentam um desvio padrão elevado.

O aumento da expressão de p53 foi verificado em neoplasias malignas esofágicas (BAHNASSY et al, 2005) e orais (HORTA et al, 2007). Expressão positiva de p53 parece ser um evento comum em carcinomas de cabeça e pescoço. Nossos resultados confirmam observações anteriores de alta expressão de p53 em carcinomas de laringe (PRUNERI et al, 1998, NARAYANA et al, 1998, KASKAYASI et al, 2001, KLATKA, 2001).

Estudos indicam que a baixa expressão de p27 está associada ao mau prognóstico em vários tipos de tumores. Na laringe, redução da expressão de p27 correlaciona-se a com progressão de lesões pré-cancerosas e com um comportamento agressivo dos tumores (HIRAI, 2003, TAMURA, 2001). Resultados similares em câncer de esôfago também demonstraram uma associação entre alta expressão de p27 e estágio da doença avançado (Anayama et al., 1998). Entretanto a alta expressão de p27 encontrada no presente estudo coincide com os dados de Korkmaz e colaboradores (2005).

Amplificação ou alta expressão de Mdm2 é uma alteração bastante comum, detectado principalmente em sarcomas. Segundo Agarwal e colaboradores (1999), alta expressão de Mdm2 freqüentemente ocorre em lesões pré-neoplásicas e neoplásicas de mucosa oral. Em laringe são escassos os estudos a respeito dessa proteína. Em nosso estudo a alta expressão de Mdm2 concorda com os resultados obtidos por Pruneri e colaboradores (1997).

Na tabela 5 nota-se que as proteínas p53, p27 e Mdm2 permanecem praticamente constantes tanto na lesão primária $\left(\mathrm{LSCC}^{\mathrm{W}}\right)$ quanto nos respectivos linfonodos (LB).

O teste de Wilcoxon para amostras pareadas demonstrou que não há diferenças significantes entre os níveis de expressão de cada proteína entre os dois tipos de lesões. 
O teste de correlação de Spearman demonstrou que os níveis de expressão nos dois tipos de lesões estão significantemente correlacionados ao nível de significância de $1 \%$ $(\mathrm{p}<0,01)$. De acordo com os coeficientes de correlação de Spearman (r) podemos verificar que a proteína p53 mostrou maior correlação entre a lesão primária e o linfonodo, seguida da proteína Mdm2 e da p27. Cabanillas e colaboradores (2007) também encontraram uma correlação estatisticamente significante entre expressão de p53 na lesão primária e seu foco metastático.

De acordo com o teste de correlação para postos de Spearman mostrado na tabela 6 , feito para a análise da correlação entre diferentes proteínas em cada tipo de lesão, nenhum dos coeficientes calculados se mostrou significante. Entretanto, observa-se uma tendência de correlação positiva entre p27 e Mdm2 em $\operatorname{LSCC}^{\mathrm{Wt}}$ (valor de $p$ marginalmente significativo ligeiramente superior a 0,05), isto é, quanto maior o nível de expressão de uma proteína, maior será o da outra. A mesma tendência de correlação positiva também foi observada entre p53 e $\operatorname{Mdm} 2 \mathrm{em} \mathrm{LSCC}{ }^{\mathrm{W}}$.

\section{- quanto aos tipos de HPV e expressão imunoistoquímica de p53, p27 e Mdm2}

Segundo Rabah e colaboradores (2000) em carcinomas associados à infecção por HPV não ocorrem mutações em p53. Deste modo a proteína E6 do HPV poderia se ligar à p53 e induzir sua degradação. Outros estudos têm mostrado que mutações em p53 e infecção por HPV podem coexistir (SNIJDERS et al, 1994).

O anticorpo p53 utilizado neste trabalho reage tanto com o tipo selvagem quanto o tipo mutante de p53, impossibilitando a discriminação citada acima.

De acordo com a tabela 7 observou-se ausência de expressão de p53 nos casos HPV positivos, o que poderia sugerir que a proteína p53 estaria sendo degradada tanto pela presença 
do HPV quanto pela ação de Mdm2 que se encontra elevada. Já nos casos HPV negativos não existe a contribuição parcial do HPV e por isso há um conseqüente aumento de p53 (35,8\%). Isso é comprovado pelo fato da expressão de Mdm2 permanecer aproximadamente constante entre os casos HPV positivos $(66,1 \%)$ e HPV negativos $(67,5 \%)$.

A ampla variação da expressão de p27 (0 a 92,7\%) e Mdm2 (13.6 a 91,8\%) não nos permite chegar a uma conclusão precisa do comportamento dessas proteínas quanto aos tipos de HPV presentes, já que o número de casos positivos para cada tipo de HPV (n=1) foi muito pequeno. 
6 CONCLUSÕES 


\section{- quanto ao Câncer de laringe e Parâmetros Clínicos}

Sexo, idade, fumo e álcool não são considerados bons parâmetros para diferenciar grupos de carcinomas invasivos laríngeos com metástase e sem metástase.

Confirmou-se a maior incidência de carcinoma de laringe com e sem metástase no sexo masculino e para indivíduos que consumem álcool e cigarros com idade média de 56 a 59 anos.

\section{- quanto a Detecção e Tipagem do HPV}

A taxa de detecção do HPV na população estudada foi de $7.4 \%$, estando aproximadamente dentro do intervalo percentual observado na literatura (8 a 58\%). A discrepância observada entre as porcentagens dos trabalhos pode estar relacionada com a variação de sensibilidade do método utilizado e com a diversidade populacional estudada.

Os tipos de HPV presentes na amostra analisada foram HPV 6, 16, 31 e 33. Os HPVs 11 e 18 não foram encontrados. Devido à baixa porcentagem de amostras HPV positivas neste estudo não foi possível concluir quais são os tipos virais predominantes.

- quanto ao carcinoma invasivo de laringe e a expressão imunoistoquímica de p53, p27 e

\section{$\operatorname{Mdm} 2$}

- A alta expressão de p53, p27 e Mdm2 e a diferença estatisticamente não significante em $\mathrm{LSCC}^{\mathrm{W}}$ e $\mathrm{LSCC}^{\mathrm{WT}}$ nos levam a concluir que estas proteínas não são consideradas bons parâmetros para diferenciar lesões com e sem metástase.

- O teste de correlação para postos de Spearman revelou que não há qualquer correlação entre os níveis de expressão de p53, p27 e Mdm2 quando combinados dois a dois entre as lesões com metástase, sem metástase e linfonodos. 
- quanto aos tipos de HPV e expressão das proteínas p53, p27 e Mdm2

Provavelmente tanto a proteína E6 do HPV quanto a proteína Mdm2 degradam a p53 em pacientes HPV positivos. Isso pode ser comprovado através do nível aproximadamente constante de Mdm2 tanto nos casos HPV positivos como nos HPV negativos.

Na ausência do HPV, a degradação da p53 se dá exclusivamente através da Mdm2.

Não há uma relação evidente entre p27 e Mdm2 com os tipos de HPV, necessitando outros estudos para determinar se oncoproteínas virais poderiam estar envolvidas na regulação de outros componentes, intrínsecos ou extrínsecos, no carcinoma de laringe. 
7 REFERÊNCIAS BIBLIOGRÁFICAS 
ABDEL-FATTAH, G.; YOFFE, B.; KRISHNAN, B.; KHAOUSTOV, V.; ITANI, K. MDM2/p53 protein expression in the development of colorectal adenocarcinoma. $\mathbf{J}$ Gastrointest Surg., Texas, USA, v. 4, p. 109-14, 2000.

AGARWAL, S.; MATHUR, M.; SRIVASTAVA, A.; RALHAN, R. MDM2/p53 co-expression in oral premalignant and malignant lesions: potential prognostic implications. Oral Oncol., New Delhi, India, v. 35, p.209-16, 1999.

AGUDELO, D.; QUER, M.; LEON, X.; DÍEZ, S.; BURQUÉS, J. Laryngeal carcinoma in patients without a history of tobacco and alcohol use. Head Neck., Barcelona, Spain, v. 19, p. 200-204, 1997.

ALBERTS, B.; BRAY, D.; LEWIS, J.; RAFF, M.; ROBERTS, K. \& WATSON, J.D. - The Cell ARTES MÉDICAS. $4^{\mathrm{a}}$ ed. Porto Alegre (RS), 2002..

ALMADORI, G. ; CADONI, G. ; CATTANI, P.; GALLI, J. ; BUSSU, F. ; FERRANDINA, G.; SCAMBIA, G.; FADDA, G.; MAURIZI, M. Human papillomavirus infection and epidermal growth factor receptor expression in primary laryngeal squamous cell carcinoma. Clin Cancer Res., Rome, Italy, v. 7, p. 3988-93, 2001.

ALTIERI, A.; GARAVELLO, W.; BOSETTI, C.; GALLUS, S.; LAVECCHIA, C. Alcohol consumption and risk of laryngeal cancer. Oral Oncol., Milan, Italy, v.41, p.956-65, 2005. 
ATULA, S.; GRENMAN, R.; KUJARI, H.; SYRJÄNE, S. Detection of Human Papillomavirus (HPV) in laryngeal carcinoma cell lines provides evidence for a heterogeneic cell population. European Journal of Cancer., Turku, v.35, p. 825-832,1999.

BAHNASSY, A.A.; ZEKRI, A.R.; ABDALLAH, S.; EL-SHEHABY, A.M.; SHEREH, G.M. Human papillomavirus infection in Egyptian esophageal carcinoma: correalation with p53, p21, mdm2, c-erbmpact survival. Pathol Int., Cairo, Egypt, v.55, p.53-62, 2005.

BARTKOVA, J.; LUKAS, J.; MÜLLER, H.; STRAUSS, M.; GUSTERSON, B.; BARTEK, J. Abnormal patterns of D-type cyclin expression and g1 regulation in human head and neck cancer. Cancer Res., Copenhagen, v.55, p.949-56, 1995.

BLOOM, J.; PAGANO, M. Deregulated degradation of the CDK inhibitors and malignant transformation. Sem. Cancer Biol., New York, v.13, p. 41-47, 2003.

BOSCH, F.X., RITTER, D., ENDERS, C., FLECHTENMACHER, C., ABEL, U., DIETZ, A., HERGENHAHN, M., WEIDAUER, H. Head and neck tumor sites differ in prevalence and spectrum of p53 alterations but these have limited prognostic value. Int. J. Cancer., Heidelberg, Germany, v. 111, p. 530-538, 2004.

BRITO,H.; VASSALLO, J.; ALTEMANI, A. Detection of human papillomavirus in laryngeal squamous dysplasia and carcinoma. An in situ hybridization and signal amplification study. Acta Otolaryngol., Campinas, Brazil, v.120, p. 540-4, 2000. 
CABANILlAS, R.; RODRIGO, J.P.; ASTUDIllO, A.; DOMÍNGUEZ, F.; SUÁREZ, C.; CHIARA, MD. p53 expression in squamous cell carcinoma of the supraglottic larynx and its lymph node metastases. Cancer., Oviedo, Spain, v.109, p.1791-1798, 2007.

CASON, J.; BEST, J.M.; RAJU, K.S. Vertical transmission of human papillomavirus. Am J Obstet Gynecol. v. 180, p. 774-5, 1999.

CHEAH, P.L.; LOOI, L.M. Biology and pathological associations of the human papillomaviruses: a review. Malays J Pathol., Kuala Lumpur, v.20, p. 1-10, 1998.

CHETTY, R. Cyclin E and p27: two proteins on see-saw or another false down? Histopathology., Durban, v.40, p.393-394, 2002.

COOPER, G.M; HAUSMAN, R.E. The Cell. A Molecular Approach. 3. ed. Sunderland, MA, 2003.

COQUERET, O. .New roles for p21 and p27 cell-cycle inhibitors: a function for each cell compartment. Trends in Cell Biol. v.3, p. 65-70, 2000.

DE VILLIERS, E.M. Papillomavirus and HPV typing. Clin Dermatol., Heidelberg, Germany, v. 15, p. 199-206, 1997.

DE VILLIERS, E.M.; FAUQUET, C.; BROKER, T.R.; BERNARD, H.U.; ZUR HAUSEN, H. Classification of papillomaviruses. Virology., Heidelberg, Germany, v.324, p. 17-27, 2004. 
DIKSHIT, R.P; BOFFETA, P.; BOUCHARDY, C. MERLETT, F.; CROSIGNANI, P.; CUCHI, T. ARDANAZ, E.; BRENNAN, P. Lifestyle habits as prognostic factors in survival of laryngeal and hypopharyngeal cancer: a multicentric European study. Int J Cancer., Lyon, France, v.117, p. 992-995, 2005.

DOKIANAKIS, D.N.; PAPAEFTHIMIOU, M.; TSIVELEKA, A.; SPANDIDOS, D.A. High prevalence of HPV18 in correlation with ras gene mutations and clinicopathological parameters in cervical cancer studied from stained cytological smears. Oncol. Rep., Crete, Greece, v.6, p.1327-31, 1999.

DOLCETTI, R.; DOGLIONI, C.; MAESTRO, R.; GASPAROTTO, D.; BARZAN, L.; PASTORE, A.; ROMANELLI, M.; BOIOCCHI, M. p53 overexpression is an early event in the development of human squamous-cell carcinoma of the larynx: genetic and prognostic implications. Int J Cancer., Aviano, Italy, v. 52, p.178-82, 1992.

DOSEMECI, M.; GOKEMEN, I.; UNSAL, M.; HAYES, R.G.; BAIR, A. Tobacco, alcohol use, and risk of laryngeal and lung cancer by subsite and histologic type in Turkey. Cancer Causes Control., Maryland, USA, v.8, p. 729-37, 1997.

EL-SERAG, H.B.; HEPWORTH, E.J.; LEE, P.; SONNENBERG, A. Gastroesophageal reflux disease is a risk factor for laryngeal and pharyngeal cancer. Am J Gastroenterol., Texas, USA,v.96, p. 2013-8, 2001.

ERDAMAR, B.; KELES, N.; KAUR, A.; SUOGLU, Y.; KIYAK, E. Expression of the cyclinkinase inhibitors $\mathrm{p} 21^{(\mathrm{WAF} 1)}$ and $\mathrm{p} 27^{(\mathrm{KIP} 1)}$ and the $\mathrm{p} 53$ tumor supressor genes in adult-onset 
laryngeal papillomas. Eur.Arch.Otorhinolaryngol., Istambul, Turkey, v.259, p.516-520, 2002.

FERLAY, J.; BRAY, F.; PIZANI, P.; PARKIN, D.M. Globocan 2000: cancer incidence, mortality and prevalence worldwide. Version 1. International Agency for Research on Cancer (IARC). Cancer base No. 5. Lyon (France); IARC Press, 2001.

FREEDMAN, D. A.; LEVINE, A. J. Nuclear export is required for degradation of endogenous p53 by MDM2 and human papillomavirus E6. Mol.Cel. Biol., New Jersey, USA, v.18, p. 7288-7293, 1998.

GARCÍA-MILIÁN, R.; HERNÁNDEZ, H.; PANADÉ, L.; RODRÍGUEZ, C.; GONZÁLEZ, N.; VALENZUELA, C.; ARAÑA, M.D.J.; PEREA, S.E. Detection and typing of human papillomavirus DNA in benign and malignant tumours of larymgeal epithelium. Acta Otolaryngol (Stockh)., Havana, Cuba, v.118, p. 754-758,1998.

GAYLES, B.; HAYDEN, R.E. Recurrent respiratory papillomatosis: progression to invasion and malignancy. Am J Otolaryngol., St. Louis, v.12, p.104-112,1991.

GO, C.; SCHWARTZ, M.R.; DONOVAN, D.T. Molecular transformation of recurrent respiratory papillomatosis : viral typing and p53 overexpression. Ann Otol Rhinol Laryngol., Houston, Texas, v. 112, p. 298-302, 2003. 
GOIATO, M.C.; FERNANDES, A.U.R.; SANTOS, D.M.; NETO, S.C. Perfil de pacientes acometido por câncer de laringe atendidos no centro de oncologia bucal - UNESP. Revista Odonto Ciência (Journal of Dental Science). v. 21, p. 3 - 8, 2006.

GOLIAS, C.H.; CHARALABOPOULOS, A.; CHARALABOPOULOS, K. Cell proliferation and cell cycle control: a mini review. J Clin Pract. v.58, p. 1134-1141, 2004.

GONZALEZ-MOLES, M.A.; RODRIGUEZ-ARCHILLA， A.; RUIZ-AVILA， I.; GONZALEZ-MOLES, S.; MARFIL-ALVAREZ, R. Increase of proliferating cell nuclear antigen (PCNA) expression in HPV-18 positive oral squamous cell carcinomas. Acta Stomatol Belg., Spain, v.93, p.113-8, 1996.

GORGOULIS, V.G.; ZACHARATOS, P.; KOTSINAS, A.; KYROUDI, A.; RASSIDAKIS, A.N.; IKONOMOPOULOS, J.A.; BARBATIS, C.; HERRINGTON, C.S.; KITTAS, C. Human papillomavirus (HPV) is possibly involved in laryngeal but not in lung carcinogenesis. Hum Pathol.Athens., Greece, v.30, p. 274-83,1999.

GUO-KANG, F.; SHIGEHARU, F.; HIROSHI, S.; TSUZUKI, H.; ITO, N.; SAITO, H. Expression of protein p27 is associated with progression and prognosis in laryngeal cancer. The Laryngoscope., v.109, p. 815-820, 1999.

HARDISSON, D. Molecular pathogenesis of head and neck squamous cell carcinoma.Eur Ach Otorhinolaryngol., Madrid, Spain, v. 260, p. 502-8, 2003. 
HARPER, J.W.; ADAMS, P.D. Cyclin dependent kinase. Chem. Rev., Texas, USA, v.8, p.2511-26, 1993.

HARRIS, S.L.; LEVINE, A.J. The p53 pathway: positive and negative feedback loops. Oncogene., New Jersey, v. 24, p. 2899-908, 2005.

HEISE, A. The Clinical Significance of HPV. The Nurse Practitioner., Ontario, Canada, v.28, p.8-19, 2003.

HERRERO, R. Chapter 7: Human papillomavirus and cancer of the upper aerodigestive tract. J Natl Cancer Inst Monogr., Santa Rosa, Costa Rica, v. 31, p. 47-51, 2003.

HIRAI. T.; HAYASHI, K.; TAKUMIDA, M.; UEDA, T.; HIRAKAWA, K.; YAJIN, K. Reduced expression of $\mathrm{p} 27$ is correlate with progression precancerous lesions in larynx.Auris NasusLarynx., Minami-Ku, Japan, v.30, p.163-168, 2003.

HIRANO, M.; SATO, K. Histological color atlas of the human larynx. San Diego, p.1-36, 1993.

HONDA, R.; TANAKA, H.; YASUDA, H. Oncoprotein mdm2 is an ubiquitin ligase E3 for tumor suppressor p53. FEBS Lett., Tokyo, Japan, v.420, p.25-27, 1997.

HORIE, S.; MAETA, H.; ENDO, K.; UETA, T.; TAKASHIMA, K.; TERADA, T. Overexpression of p53 protein and MDM2 in papillary carcinomas of the tyroid: Correlation with clinicopathologic features. Pathol Int., Tottori, Japan, v. 51, p. 11-5, 2001. 
HORTA, M.C.; DE ASSIS, L.A.; DE SOUZA, A.F.; DE ARAÚJO, V.C. p53 and p21 WAF/cip1 overexpression at the invasive front of lower lip squamous cell carcinoma. J Oral Pathol Med., Belo Horizonte, Brazil, v. 36, p.88-92, 2007.

HOWLEY, P.M.; SCHEFFNER M.; ROMANCZUK H.; MUNGER K.; HUIBREGTSE J.M.; MIETZ J.A. Functions of human papillomavirus proteins. Curr Top Microbiol Immunol.,v.186, p.83-99, 1994.

HWANG, C.F.; SU, C.Y.; HUANG, S.C.; HUANG, C.C.; FANG, F.M.; LUI, C.C.; CHANG, H.W.; CHO, C.L. Low expression levels of p27 correlate with loco-regional recurrence in nasopharyngeal carcinoma.Cancer Lett., Taiwan, v.28, p. 231-6, 2003.

INSTITUTO NACIONAL DE CÂNCER (INCA, BRASIL). Epidemiologia. disponível em: http://www.inca.org.br, data de acesso 12/04/2008.

IWASAWA, A.; NIEMINEN, P.; LEHTINEN, M.; PAAVONEN, J. Human Papillomavirus in squamous cell carcinoma of the vulva by polymerase chain reaction. Obest.Gynecol., Helsinki, Finland, v.89, p. 81-84, 1997.

JACOB, S.E.; SREEVIDYA, S.; CHACKO, E.; RADHAKRISHNA PILLAI, M. Cellular manifestations of human papillomavirus infection in laryngeal tissues. Journal of Surgical Oncology., India, v.79, p.142-150, 2002. 
KASHIMA, H.K.; SHAH, F.; LYLES, A.; GLACKIN, R.; MUHAMMAD, N.; TURNER L. A comparison of risk factors in juvenile-onset and adult-onset recurrent respiratory papillomatosis. Laryngoscope., Baltimore, USA, v.102, p.9-13, 1992.

KASKAYASI, M.; HÜCÜMENOGLU， S.; SIRINER， G.I.; HÜCÜMENOGLU， M.; Overexpression pf p53 and c-erbB-2 oncoproteins in laryngeal carcinoma. Eur Arch Otorhinolaryngol., v.258, p. 329-335, 2001.

KAYA, H. ; KOTILOGLU, E. ; INANLI, S. ; EKICIOGLU, G.; BOZKURT, S.U. ; TUTKUN, A. ; KÜLLÜ, S. Prevalence of human papillomavirus (HPV) DNA in larynx and lung carcinomas. Pathologica., Istanbul, Turkey, v. 93, p. 531-4, 2001.

KHOO, M.L.C.; BRASLEY, N.J.P; EZZAT, S.; FREEEMAN, J.L.; ASA, S.L. Overexpression of cyclin D1 and underexpression of p27 predict lymph node metastases in papillary thyroid carcinoma. J. clin. Endocrinol Metab.,v. 87,p. 1814-8, 2002.

KIM, D.H.; LEE, H.I.; NAM, E.S.; SHIN, H.S.; SOHN, J.H.; PARK, C.H.; YOON, D.S.; SONG, S.Y.; PARK. Y.E. Reduced expression of the cell-cycle inhibitor p27Kip1 is associated with progression and lymph node metastasis of gastric carcinoma. Histopathology., Seoul, Korea, v.36, p.245-51, 2000.

KIM, K.H.; KIM, Y.S. Role of HPV and p53 suppressor gene in cervical carcinogenesis. Yonsei Med., Seoul, Korea, v.36, p.412-425, 1995. 
KLAES, R.; FRIEDRICH, T.; SPITKOVSKY, D.; RIDDER, R.; RUDY, W.; PETRY, U.; DALLENBACH-HELLWEG， G.; SCHMIDT, D.; VON KNEBEL DOEBERITZ, M. Overexpression of p16 INK4a as a specific marker for dysplastic and neoplastic epithelial cells of the cervix uteri. Int. J. Cancer., Heidelberg, Germany, v.92, p.276-284, 2001.

KLATKA, J. Prognostic value of the expression of p53 and bcl-2 in patients with laryngeal carcinoma. Eur Arch Otorhinolaryngol., Lublin, Poland, v. 258, p537-541, 2001.

KORKMAZ, H., DU, W., YOO, G.H., ENAMORADO, I.I., LIN, H.S., ADSY, V., KEWSON, D., ENSLEY, J.F., SHIBUYA, T.Y., JABOBS, J.R., KIM, H. Prognostic significance of G1 cell-cycle inhibitors in early laryngeal cancer. American Journal of Otolaryngology-Head and Neck Medicine and Surgery., Detroit, USA, v. 26, p.77-82, 2005.

KREIMER, A.R.; CLIFFORD, G.M.; BOYLE, P.; FRANCESCHI, S. Human papillomavirus type in head and neck squamous cell carcinomas worldwide: a systematic review. Cancer Epidemiol Biomarkers Prev., Lyon, France, v.14, p. 467-75, 2005.

KUDO, Y.; KITAJJMA, S; SATO, S.; MIYAUCHI, M.; OGAWA, I.; TAKATA, T. Establishment of an oral squamous cell carcinoma cell line with high invasive and p27 degradation activities from a lymph node metastasis.Oral Oncol., Hiroshima, Japan, v.39, p.515-520, 2005.

KUO, M.Y.P.; HSU, H.J.; KOK, S.H.; KUO, R.C.; YANG, H.; HANH, L.J.; CHIANG, C.P. Prognostic role of p27 kip1 expression in oral squamous cell carcinoma in Taiwan. Oral Oncology., Taipei, Taiean, v.38, p.172-178, 2002. 
KUROPKAT, C.; VENKATESAN, T. K.; CALDARELLI, D.D.; PANJE, W. R.; HUTCHINSON, J.; PREISLER, H. D.; COON, J. S.; WERNER, J.A.- Abnormalities of molecular regulators of proliferation and apoptosis in carcinoma of the oral cavity and oropharynx. Auris Nasus Larynx., Marburg, Germany, v.29: p.165-174, 2002.

LACY, E.R.; FILIPPOV, I.; LEWIS, W.S.; OTIENO, S.; XIAO, L.; WEISS, S.; HENGST, L.; KRIWACKI, R.W. p27 binds cyclin-CDK complexes through a sequential mechanism involving binding-induced protein folding. Nat struct Mol Biol., Memphis, USA, v. 11, p. 358-64, 2004.

LI， X.J.; MURAI, M.; KOYAMA, T. ; WANG, D.Y.; HASHIMOTO, K. MDM2 overexpression with alteration of the p53 protein and gene status in oral carcinogenesis. Jpn J Cancer Res., Hamamatsu, Japan, v. 91, p. 492-8, 2000.

LIE, E.S.; ENGH, V.; BOYSEN, M. ET AL. Squamous cell carcinoma of the respiratory tract following laryngeal papillomatosis. Acta Otolaryngol (Stockh)., Oslo, Norway, v.114, p.209212, 1994.

LINDEBERG, H.; KROGDAHL, A. Laryngeal cancer and human papillomavirus: HPV is absent in the majority of laryngeal carcinomas. Cancer Letters. v. 46, p. 9-13, 1999.

LIU, M.; LAWSON, G.; DELOS, M.; JAMART. J.; CHATELAIN, B.; REMEACLE, M.; MARBAIX, E. Prognostic value of cell proliferation markers, tumor suppressor proteins and 
cell adhesion molecules in primary squamous cell carcinoma of the larynx and hypopharynx. Eur.Arch.Otorhinolaryngol., Belgium, v.260, p. 28-34, 2003.

MAO, E.J. Prevalence of human papillomavirus 16 and nucleolar organizer region counts in oral exfoliated cells from normal and malignant epithelia. Oral Surg. Oral Med. Oral Pathol. Oral Radiol. Endod.,Sheffield, v.80, p.320-9, 1995.

MENDHELSON, J.; HOWLEY, P.M.; ISRAEL, M.A.; LIOTTA, L.A. The molecular basis of cancer.2nd edition.WB.Saunders Company.Philadelphia. Pennsylvania. p.691, 2001.

MORSHED. K., KOROBOWICZ, E., SZYMANSKI, M., SKOMRA, D., GOABEK, W. Immunohistochemical demonstration of multiple HPV types in laryngeal squamous cell carcinoma. Eur Arch Otorhinolayngol., Lublin, Poland, v. 262, p. 917-920, 2005.

MÜNGER, K.; HOWLEY, P.M. Human papillomavirus immortalization and transformation functions. Virus Res., Boston, USA, v. 2, p.213-228, 2002.

MURAKAMI, M.S.; WOUDE, G.F.V. Regulation of the cell cycle. In: MENDELSOHN, J.; HOWLEY, P.M.; ISRAEL, M.A.; LIOTTA, L.A. The molecular basis of cancer. $2^{\text {nd }}$ ed. Philadelphia: W.B. Saunders Company.p.10-17, 2001.

MUSCAT, J.E.; WYNDER, E.L.; Diesel exhaust, diesel fumes, and laryngeal cancer. Otolaryngol. Head Neck Surg., New York, USA, v.112, p.437-440, 1995. 
NADAL, A.; CAMPO, E.; PINTO, J.; MALlOFRÉ, C.; PALACÍN, A.; ARIAS, C.; TRASERRA, J.; CARDESA, A. p53 expression in normal, dysplasic, and neoplastic laryngeal epithelium. Absence of correlation with prognostic factors. J Pathol., Barcelona, Spain, v. 175, p. $181-8,1995$.

NARAYANA A.; VAUGHAN, A.T.; GUNARATNE, S.; KATHURIA, S.; WALTER, S. A.; REDDY, S.P. Is p53 an independent prognostic factor in patients with laryngeal carcinoma? Cancer., Illinois, USA, v. 82, p.286-291, 1998.

ONEL, K.; CORDON-CARDO, C. MDM2 and prognosis. Mol Cancer Res., New York, USA, v. 2, p. 1-8, 2004.

PARKIN, D.M.; BRAY, F.; FERLAY, J.; PISANI, P. Global cancer statistics, 2002. CA Cancer J Clin. Lyon, France, v. 55, p.74-108, 2005.

PEREZ-AYALA, M.; RUIZ-CABELlO,F.; ESTEBAN, F.; ET AL. Presence of HPV 16 sequence in laryngeal carcinomas. Int J Cancer., Granada, Spain, v.46, p. 8-11, 1990.

PFISTER, H. Chapter 8: Human papillonavirus and skin cancer. J Natl Cancer Inst Monogr., Cologne, Germany, v. 31, p. 52-6, 2003.

PFISTER, H.; FUCHS, P.G. Anatomy, taxonomy and evolution of papillomaviruses. Intervirol. v.37, p.143-49, 1994. 
PIGNATARO, L., SAMBATARO, G., PAGANI, G., PRUNERI, G. Clinico-prognostic value of D-types cyclins and p27 in laryngeal cancer patients: a review. Acta Otorhinolaryngol Ital., Italy, v.25, p. 75-85, 2005.

PRUNERI, G.; PIGNATARO, L.; CARBONI, N. ; RONCHETTI, D. ; CESANA，B.M.; OTTAVIANI, A.; NERI, A.; BUFFA, R. Clinical relevance of p53 and bcl-2 protein overexpression in laryngeal squamous cell carcinoma. Int J Cancer., Milan, Italy, v. 79, p. 262-8, 1998.

PRUNERI, G.; PIGNATARO, L.; CARBONI, N.; BUFFA, R.; DI FINIZIO, D.; CESANA B.M.; NERI, A. Clinical relevance of expression of the CIP/KIP cell-cycle inhibitors p21 and p27 in laryngeal cancer. J.Clin.Oncol., Milan, Italy, v.17: p. 3150-3159, 1999.

PRUNERI, G.; PIGNATARO, L.; CARBONI, N.; LUMINARI, S. ; CAPACCIO, P. ; NERI, A.; BUFFA, F. MDM-2 oncoprotein overexpression in laryngeal squamous cell carcinoma: association with wild-type p53 accumulation. Mod Pathol., Milan, Italy, v. 10, p. 785-92, 1997.

QADEER , M.A.; COLABIANCHI, N.; STROME, M.; VAEZI, M.F. Gastroesophageal reflux and laryngeal cancer: causation or association? A critical review. Am J Otolaryngol. Clevelan, USA, v. 27. p. 119-28, 2006.

RABAH, R.; SARKR, W.; THOMAS, R.; LANCASTER, W.D.; GREGOIRE, L. Human papillomavirus type, proliferative activity and $\mathrm{p} 53$ : potential markers of agressive papillomatosis. Arch Pathol., Detroit, USA, v.124, p.721-4, 2000. 
RITCHIE, J.M.; SMITH, E.M.; SUMMERSGILL，K.F.; HOFFMAN，H.T.; WANG，D.; KLUSSMANN, J.P.; TUREK, L.P.; HAUGEN, T.H. Human papillomavirus infection as a prognostic factor in carcinomas of the oral cavity and oropharynx. Int J Cancer., Iowa, USA, v.104, p.336-44, 2003.

SANGUINETTI, C.J.; DIAS NETO, E.; SIMPSON,A.J. Rapid silver staining and recovery of PCR products separeted on polyacrylamide gels. Biotechniques., Natick, v.17, p.914-21, 1994.

SARTOR, S.G.; ELUF-NEO, J.; TRAVIER, N.; WÜNSCH FILHO, V.; ARCURI, A.S.; KOWALSKI, L.P.; BOFFETTA, P. Occupational risks for laryngeal cancer: a case-control study. Cad Saude Publica. São Paulo, Brazil, v. 23, p. 1473-81, 2007.

SCHEURLEN, W.; STREMLAU, A.; GISSMAN, L.; HOHN, D.; ZENNER, H.P.; ZUR HAUSEN, H. Rearranges HPV 16 molecules in an anal and in a laryngeal carcinoma. Int J Cancer. v.38, p. 671-676,1986.

SCULLY, C.; FIELD, J.; TANZAWA, H. Genetic abrrations in oral or head and neck squamous cell carcinoma(SCCHN):1. Carcinogen metabolism, DNA repair and cell cicle control. Oral.Oncol., London, UK, v.36, p.256-63, 2000.

SHEER, C.J. Cancer cell cycles. Science., Memphis, USA, v. 274, p. 1672-7, 1996. 
SKOMEDAL, H.; KRISTENSEN, M.D.; LIE, A.K.; HOLM, R.H. -Aberrant expression of the cell associated proteins TP53, MDM2, p21, p27, cdk4, cyclin D1, RB, and EGRF in cervical carcinomas. Gynecol. Oncol., Oslo, Norway, v.73, p. 223-228, 1999.

SMITH, E.M.; RITCHIE, J.M.; SUMMERSGILL, K.F.; KLUSSMANN, J.P.; LEE, J.H.; WANG, D.; HAUGEN, T.H.; TUREK, L.P. Age, sexual behavior and human papillomavirus infection in oral cavity and oropharyngeal cancers. Int J Cancer., Iowa, USA, v.108, p.766-72, 2004

SNIDJERS , P.J.; STEENBERGEN, R.D.; TOP, B.; SCOTT, S.D.; MEIJER, C.J.; WALBOMERS, J.M. Analysis of p53 status in tonsillar carcinomas associated with human papillomavirus. J Gen Virol., Amsterdan, Netherlands, v. 75, p. 2769-75, 1994.

SOUSSI, T.; LOZANO, G. p53 mutation heterogeneity in cancer. Biochem Biophys Res Commun., Paris, France. v. 331, p. 834-42, 2005.

SOUZA, P.E.; MESQUITA, R.A.; GOMEZ, R.S. Evaluation of p53, PCNA, Ki-67, MDM2 and AgNOR in oral peripheral and central giant cell lesions. Oral Dis., Minas Gerais, v.6, p.35-9, 2000.

SOUZA, R.; DOSTATNI, N.; YANIV, M. Control of papillomaviruse gene expression. Biochimica Biophysica Acta., Paris, France, v.1032, p. 19-37, 1990. 
SYRJÄNEN, K.; SYRJÄNEN, S.; PYRHÖNEN, S. Human papilloma virus (HPV) antigens in lesions of laryngeal squamous cell carcinomas. ORL J Otorhinolaryngol Relat Spec., v. 44, p.323-34, 1982.

SYRJÄNEN, K.J.; SURJÄNEN, S.M. Histological evidence for the presence of condylomatous epithelial lesions in association with laryngeal squamous cell carcinoma. ORL J Otorhinolaryngol Relat Spec., v. 43, p. 181-94,1981.

SYRJÄNEN, S. Human papillomavirus (HPV) in head and neck cancer. J Clin Virol., Turku, Finland, v. 32, p. 59-66, 2005.

SYRJANEN, S.; SYRJANEN, K.; MANTYJARVI, R.; COLLAN, Y.; KARJA, J. Human papillomaviruse DNA in squamous cell carcinomas of the larynx demonstrated by in situ DNA hybridization. ORL.v. 49, p. 175-186,1987.

TALAMINI, R.; BOSETTI, C.; LA VECCHIA, C. ; DAL MASO, L. ; LEVI, F. ; BIDOLI, E. ; NEGRI, E. ; PASCHE, C. ; CAVARELLA, S. ; BARZAN, L.; FRANCESCHI, S. Combined effect of tobacco and alcohol on laryngeal cancer risk: a case-control study. Aviano, Spain, v.13, p.957-964, 2002.

TAMURA, N.; DONG, Y.; SUI, L.; TAI, Y.; SUGIMOTO, K.; NAGAHATA, S.; TOKUDA, M. Cyclin-dependent kinase inhibitor p27 is related to cell proliferation and prognosis in laryngeal squamous cell carcinoma. J Laryngol Otol., , Kagawa, Japan, v. 115, p. 400-6, 2001. 
TING, Y.; MANOS, M. Detection and typing of genital human papillomaviruses. In: INNIS, M.A.; GELFAND, D.H.; SNINSKY, J.J. (Eds) polymerase chein reaction proteocols: a guide to methods and applications. San Diego: Academic Press, p. 356-367, 1990.

TORRENTE, M.C.; AMPUERO, S.; ABUD, M., OJEDA, J.M. Molecular detection and typing of human papillomavirus in laryngeal carcinoma specimens. Acta Otolaryngol. v.125, p. $888-893,2005$.

TRAN, N.; ROSE, B.R.; O'BRIEN, C.J. Role of human papillomavirus in the etiology of head and neck cancer. Head Neck., Sydney, Australia, v. 29, p. 64-70, 2007.

TRONCONE, G.; MARTINEZ, J.C.; PALOMBINI, L.; DE ROSA, G.; MUGICA, C.; RODRIGUEZ, J.A.; ZEPPA, P.; DI VIZIO, D.; LUCARIELLO, A.; PIRIS, M.A. Immunohistochemical expression of $\mathrm{mdm} 2$ and $\mathrm{p} 21 \mathrm{WAF} 1$ in invasive cervical cancer: correlation with p53 protein and high risk HPV infection. J. Clin. Pathol., Italy, v. 51, p. 754$760,1998$.

TUYNS, A.J.; ESTEVES, J.; RAYMOND, L.; BERRINO, F.; BENHAMOU, E.; BLANCHET, F.; BOFFETTA, P.; CROSIGNANI, P.; DEL MORAL, A.; LEHMANN, W. Cancer of the larynx/hipopharrynx, tobacco and alcohol. IARC International case-control study in Turin and Varese (Italy), Zaragoza and Navarra (Spain), Geneva (Switzerland) and Calvados (France). Int. J. Cancer.,Lyon, France, v.41, p.483-491, 1988.

VELYVITE, D. ; LAISKONIS, A. ; ULOZA, V. ; GOZDZICKA-JOZEFIAK, A. Prevalence of human papillomavirus infection among patients with laryngeal papillomatosis and the effects 
of some risk factors on the persistance of papillomaviruses in the upper respiratory tract. Medicina (Kaunas)., v. 38, p. 499-504, 2002.

VENUTI, A.; MANNI, V.; MORELLO, R.;DE MARCO, F.; MARZETTI, F.; MARCANTE, M.L. Physical state and expression of human papillomaviruse in laryngeal carcinoma and surrounding normal mucosa. J Med Virol., Rome, Italy , v.60, p.396-402, 2000.

WATTS, S.L.; BREWER, E.E.; FRY, T.L. Human papillomavirus DNA types in squamous cell carcinomas of the head and neck. OralSurg Oral Med Oral Pathol. v.71, p.701-707, 1991.

WÜNSCH-FILHO, V. The epidemiology of laryngeal cancer in Brazil. São Paulo Med. J. v.122, p. 188-194, 2004.

YANAMOTO, S. ; KAWASAKI, G. ; YOSHITOMI, I. ; MIZUNO, A. p53, mdm2, and p21 expression in oral squamous cell carcinomas: relationship with clinicopathologic factors. Oral Surg Oral Med Oral Pathol Oral Radiol Endod., Nagasaki, Japan, v. 94, p. 593-600, 2002.

ZATONSKI, W.; BECKER, H.; LISSOWSKA, J. Tobacco, alcohol, and diet in the aetiology of laryngeal cancer: a population-based case-control study. Cancer Causes Control., Warsaw, Poland, v.2, p. 3-11, 1991.

ZHOU, B.B.; ELLEDGE, S.J. The DNA damage response: putting checkpoints in perspective. Nature., Pennsylvania, v. 6811, p. 433-9, 2000. 
ZUR HAUSEN, H. Papillomavirus infections: a major cause of human cancers. Biochim Biophys Acta., Heidelberg, Germany, v. 1288, p. F55-F78, 1996.

ZUR HAUSEN, H. Papillomaviruses and cancer: from basic studies to clinical application. Nat. Rev. Cancer., Heidelberg, Germany, v.2, p.342-350, 2002.

WALBOOMERS, J.M.; JACOBS, M.V.; MANOS, M.M.; BOSCH, F.X.; KUMMER, J.A.; SHAH, K.V.; SNIJDERS, P.J.; PETO, J.; MEIJER, C.J.; MUNOZ, N. Human papillomavirus is a necessary cause of invasive cancer worldwide. J. Pathol., Amsterdan, v.189, p.12-19, 1999. 
ANEXOS

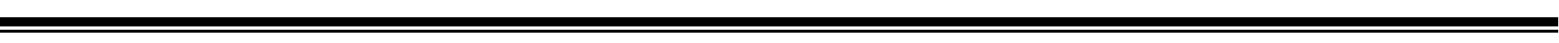




\section{Anexo A}

\section{HOSPITAL DAS CLÍNICAS DA FACULDADE DE MEDICINA DE RIBEIRÄO PRETO DA UNIVERSIDADE DE SÃO PAULO}

Ribeirão Preto, 10 de dezembro de 2004

Oficio $n^{\circ} 3389 / 2004$

$\mathrm{CEP} / \mathrm{SPC}$

Prezada Senhora:

O trabalho intitulado "EXPRESSÃO IMUNO-

HISTOQUÍMICA DAS PROTEÍNAS REGULADORAS DO CICLO CELULAR EM LESÕES DE LARINGE ASSOCIADAS Á INFECÇÃO PELO PAPILOMAVÍRUS HUMANO", foi analisado pelo Comitê de Ética em Pesquisa, em sua $194^{\text {a }}$ Reunião Ordinária realizada em 06/12/2004, e enquadrado na categoria: APROVADO, de acordo com o Processo HCRP n ${ }^{\circ} 12206 / 2004$.

Aproveito a oportunidade para apresentar a Vossa Senhoria protestos de estima e consideração.

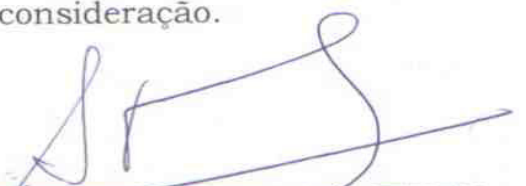

PROF. DR. SÉRGIO PEREIRA DA CUNHA

Coordenador do Comitê de Ética em Pesquisa do HCFMRP-USP e da FMRP-USP

Ilustrissima Senhora

MARCELA KAZUE HASSUMI(Orientanda)

PROF. DR. EDSON GARCIA SOARES(Orientador)

Depto. de Patologia

Em mãos 